\title{
Preferences for Redistribution and Perception of Fairness: An Experimental Study*
}

\author{
Ruben Durante $^{\dagger} \quad$ Louis Putterman ${ }^{\ddagger}$
}

July 30, 2009

\begin{abstract}
Why is there political support for progressive taxation and government transfers in western democracies? We study the importance of fairness preferences, risk aversion, and self-interest in determining support for redistribution by conducting a laboratory experiment that includes both elements not previously found together and novel features. Our design permits within-subject comparisons of the effects of earned vs. unearned sources of pre-tax-and-transfer inequality, withinsubject comparisons of choice as a disinterested observer of inequalities among others versus that as an affected party, and within-subject comparisons of choice with and without uncertainty as to own pre-tax income. Between subject variation lets us study the effects of changing the direct cost of taxation to the decision-maker and the efficiency cost to the society. We use large subject groups and the actual U.S. pre-tax income distribution to create a more macro framing than in related past experiments. We show how our results can be used to calibrate individual utility functions defined over own expected income, own income variance, social inequality, and efficiency, and we examine what the estimates mean for the median preference for redistribution and the level of redistribution that maximizes additive social welfare. Most of our subjects prefer that there be less inequality among others and demand for redistribution responds in predictable ways to the cost of taxation and to the deadweight loss associated with it. We also find that preferred levels of redistribution are highly responsive to whether or not pre-tax incomes are determined according to task performance, for male subjects, but much less so for female subjects, with this difference accounting for much of a displayed gender gap in which females prefer more redistribution.
\end{abstract}

\footnotetext{
${ }^{*}$ We are grateful to Roland Benabou, Claudia Biancotti, Samuel Bowles, Jeremy Clark, Pedro Dal Bo, Kfir Eliaz, and Jean-Robert Tyran for very helpful comments. We would also like to thank seminar participants at Brown University, Princeton University, the University of Massachusetts at Amherst, the University of Padua, the University of Trento and the University of Copenhagen, as well as participants at the ESA 2007 Conference and, the 2007 meeting of the Society for the Study of Economic Inequality (ECINEQ) and the 2008 La Pietra-Mondragone Workshop for helpful discussion. We thank Adam Rachlis for his help in initiating the set of experiments that led to this paper, and Gregory Wyckoff for rapid and efficient programming of the software used. Funding for this study was provided by the Alex C. Walker Foundation, the Steven Rattner and P. Maureen White Foundation and the Department of Economics, Brown University.

${ }^{\dagger}$ Brown University, Department of Economics. Contact: Ruben_Durante@brown.edu

${ }^{\ddagger}$ Brown University, Department of Economics. Contact: Louis_Putterman@brown.edu.
} 


\section{INTRODUCTION}

Redistribution of income through government taxes and transfers has long been normal practice in industrial democracies. Using data from the Luxembourg Income Study, Branko Milanovic (2000) estimated that the income share of the bottom two quintiles of households in 14 OECD countries in the early 1990s was on average $14.7 \%$ higher when measured on a post-tax-and-transfer than on a pre-tax-and-transfer basis. Even in the U.S., the least redistributive of the wealthy industrialized countries, Milanovic found a difference of almost $8 \%$ between the income share of the bottom $40 \%$ of households after versus before taxes and transfers.

The question of how much redistribution there ought to be is one that in the end must cross the boundary between positive and normative discussion. But there are many points on which positive economic analysis can be helpful. Studies that attempt to estimate the magnitude of the trade-off between equality and efficiency are one example. An understanding of why income is redistributed can also be pursued as a matter of positive analysis.

Among the possible explanations of why redistribution occurs in democracies is that there is a social consensus behind it, that is, a large majority of citizens feel better off living in a society with less inequality because it reflects their ethical values, increases their perceived personal and property security (Thurow, 1971), or some combination of these or other reasons. In the limit, redistribution could be Pareto improving, i.e. even those with high incomes could prefer some degree of redistribution to occur despite the material cost to them. If redistribution were universally preferred, then an efficient amount of redistribution could in principle be found, whether using the Pareto criterion or by a Benthamite social welfare function.

At the other end of the spectrum of explanations is the possibility that redistribution results from the combination of majority rule and self-interest, as emphasized in traditional political-economic models of redistribution (Meltzer and Richard, 1981; Alesina and Rodrik, 1994; Sinn, 1995, among others). The distribution of incomes in most societies is right-skewed, with the income of the median individual or household being

far below the arithmetic mean. Thus, assuming that a given amount of revenue has to be raised by either a head tax (taking a fixed amount per person), a flat tax (taking an equal proportion of income from each person), or a progressive tax (taking a proportion of income that is higher the greater the individual's income), a self-interested median voter will always prefer the flat over the head tax and the progressive over the flat tax, assuming absence of incentive considerations. If government expenditure benefits all more or less equally, political economy models that assume equal participation in elections always predict that progressive taxes will be adopted in market democracies. The same logic can be extended from funding of public goods to provision of health and other services to providing transfer payments. In the absence of incentive and other dynamic considerations, however, such models predict the complete leveling of incomes, something not observed in practice.

The above discussion leaves out one more important reason why self-interest might lead to redistribution: in the absence of adequate means of insuring themselves against negative shocks, individuals with average or above-average incomes may favor redistributive taxation as a form of social insurance (Benabou and Ok, 2001; Alesina and La Ferrara, 2005). For this to happen, tax regimes must be relatively persistent over time, and voters must have some degree of uncertainty about how they will fare in the future. Both these assumptions are reasonable in real contexts.

Our remarks about social or ethical preferences for redistribution are also incomplete insofar as they fail to consider that the value judgments in question may depend on the nature and causes of pre-tax inequality, and on how these are perceived by the voters. Some authors have suggested that differences in voter preferences may depend, at least in part, on their perceptions of whether the distributive outcomes of the market economy 
are perceived as fair or not (Piketty 1995; Ravallion and Lokshin, 2000; Graham and Pettinato, 2002; Alesina, et al. 2004; Alesina and Angeletos, 2005; Benabou and Tirole, 2006). Using survey data from several sources, Fong $(2001,2003)$ finds supporting evidence for the United States that such fairness considerations matter to people.

An extensive experimental literature has investigated how agents' choices in various economic interactions and games of division may be dictated by forces other than self-interest, such as aversion to inequality (Charness and Rabin, 2002; Fehr and Schmidt, 2003; Camerer, 2003) and how the origin of initial entitlements affects the extent of non-self-interested behavior (Hoffman and Spitzer, 1985; Burrows and Loomes, 1994). However, most of these studies have focused on small group interactions, and it is unclear how these findings can be generalized to explain attitudes toward equality and redistribution at the societal level. Our experiment joins a relatively small existing set of studies of preferences on redistribution that are designed with a macro-political economy application in mind and involve choices that are potentially costly in real money terms to the decisionmaker (Ackert et al., 2007; Krawczyk, 2007; Beckman et al., 2004; Beck, 1994). Studies in which respondents' statements of preference among distributions have no payoff consequences for them include Amiel and Cowell (1992), Amiel et al. (1999), Johansson-Stenman et al. (2002), and Carlson et al. (2005).

To investigate the extent of social preferences for redistribution, their sensitivity to the determinants of inequality and to perceptions of fairness, and the more general role that self-interest plays in voting for redistributive taxes, we conducted a series of laboratory decision experiments involving a large number of subjects. One goal was to shed light on the degree to which observed redistributive outcomes in democracies are explained by self-interest versus social preferences for equality. Thus, each subject in our experiments was asked to express a preference for redistribution among the micro community of participants both under the condition of being an outside observer of a distribution of income among others, and in the situation of being an affected party with a specific interest stemming from the expectation or knowledge of having a higher or lower pre-tax income. To investigate subjects' willingness to pay for income equalization and their concern over the possibly "leaky" nature of taxation and redistribution, we varied across treatments both a direct cost to the decisionmaker and an administrative or efficiency loss to recipients. We also had subjects make decisions both under uncertainty about their relative position in the pre-tax distribution and when uncertainty had been resolved. We used mainly student subjects but also a non-student adult comparison group. Our design contains several new elements, including large group size, explicit replication of an actual country's income distribution, and multiple income determination methods in combination with multiple decision contexts.

We find most subjects willing to pay to increase equality of earnings among others whom they do not know. This willingness varies in predictable ways with the direct cost to the decision-maker, and with their political views and (real world) incomes. It varies in an intuitive way with whether subjects "earn" their unequal laboratory incomes, although this difference itself is sensitive to gender in an interesting manner echoing the political "gender gap" (females are more reluctant to accept even "earned" inequality). Subjects value efficiency, redistributing less when more income is thereby lost. Despite the clear evidence of "social preferences" most subjects' choices regarding redistribution reflect their personal interest when this is also at stake. We also find a link between risk aversion and desire for redistribution. Finally, we show how subjects' decisions can be used to fit utility functions which are clearly concave in the degree of social equality and with which both the median-preferred and the (additive) social welfare maximizing level of redistribution can be calculated. Using these estimates, we compare the redistribution desired by our subjects to the levels of redistribution delivered by real-world democracies.

The remainder of the paper is organized as follows. Section 2 describes the design and rationale of our 
experiments. Section 3 provides a theoretical framework for predicting and interpreting the results. In section 4 we illustrate and discuss our main results. Section 5 concludes.

\section{EXPERIMENT DESIGN}

We designed our experiment to elicit choices with respect to redistribution of income from twenty-one participants in each of sixteen sessions. In outline, each subject first chose her preferred level of a linear tax to redistribute earnings among twenty subjects with pre-tax incomes mirroring the U.S. pre-tax income distribution. Her choice was implemented if he or she became the randomly selected dictator who earned an amount unaffected by it (or largely so) - a disinterested observer condition. Then each subject chose a level of redistributive tax for the alternative situation in which the choosers income was one of the affected twenty. Each choice was in fact a quadruple, with a separate redistributive tax level possible for each of four different determinants of initial incomes, two amenable to interpretation as earned, two not. In about half of the sessions, the second set of choices could be remade after the resolution of uncertainty about own income. Randomizations determined whether the disinterested or interested decision-maker condition held and which of the four methods determined pre-tax income rankings. Although only the eight (or twelve) choices just described are of focal concern to us, subjects required more than 90 minutes to learn the nature of their choices, make the decisions, engage in the tasks potentially determinative of own pre-tax income, make a final set of decisions providing a measure of risk aversion, and complete a background survey. A potential direct cost of redistribution to the decisive individual, and a possible efficiency loss to others, varied among sessions. We now describe the experiment in greater detail.

The sessions began with a set of instructions that appeared on the subjects' computer screens and were simultaneously read aloud by the experimenter so that all subjects were aware of facing identical rules and procedures. At the end of this first instruction stage, subjects were invited to ask questions and then answered five questions to test their comprehension of the procedures. Subjects were informed that there would be two additional parts to the experiment and that further instructions would follow.

As part of the on-screen instructions, we presented a table describing the set of provisional experimental payoffs to be assigned to each of the participants (Appendix Table 1). The distribution of the payoffs, ranging from $\$ 0.11$ to $\$ 100.00$, reproduced the distribution of the average pre-tax incomes of the lowest to highest earning twentieths of the US population, which was also included in the table. ${ }^{1}$ Participants were informed that the provisional earnings might be altered by a tax and transfer process.

In the disinterested observer condition of Part I, each subject was asked to choose a proportional tax rate $(0 \%, 10 \%, 20 \%, \ldots, 100 \%)$ to be applied to the pre-tax payoff distribution among the other twenty participants with the proceeds being distributed equally among all subjects. Participants were informed that, at the end of the session, one person would be randomly selected as the "decisive individual," and his preferred tax rate would be applied to the pre-tax earnings distribution of the other twenty participants to determine their final payoff. The decisive individual himself, however, would be affected neither by the pre-tax income profile nor by the tax and transfer to be implemented. By requiring all subjects to indicate their tax preferences at the outset, we aimed at eliciting "outside observer" preferences from the entire subject pool. We used a dictator rather than a median voter design so that subjects would have no reason to vote strategically.

Two additional dimensions of treatment variation were included in order to study agents' willingness to pay

\footnotetext{
${ }^{1}$ Appendix Table 1's reference to the distribution of income in the United States was partly intended as a framing device, to give decisions a real world macro-economic reference. However, we attempted to steer a middle course, never telling subjects, for example, that "this is an experiment to study your views about the distribution of income," never using words like "just" or "fair," etc. Compare, for example, Frohlich and Oppenheimer (1992) or Johansson-Stenman, Carlsson, and Daruvala (2002).
} 
for a more equal earnings distribution and their concern for aggregate efficiency. The first parameter (which we will refer to as 'tax cost') measures the cost of each additional 10\% tax in terms of a direct reduction in the decisive individual's payoff (compare to Andreoni and Miller, 2002). The tax cost parameter could take four alternative values: $\$ 0, \$ 0.25, \$ 0.5$, or $\$ 1$. For example, in a session with tax cost equal to $\$ 0.5$, the decisive individual was charged 50 cents for imposing a tax of $10 \%, \$ 1$ for a tax of $20 \%$, continuing up to $\$ 5$ for a tax of $100 \%$. The second parameter measures 'efficiency loss', or the loss in the aggregate payoff of the other participants associated with each additional 10\% tax, in line with Okun's (1975) "leaky bucket" argument. ${ }^{2}$ This could take three alternative values: $0 \%, 12.5 \%$, or $25 \%$. For instance, in a session with efficiency loss of $25 \%$, for each $\$ 10$ collected as tax, $\$ 2.50$ is lost and $\$ 7.50$ is divided equally among the twenty affected subjects.

Formally, the post-tax earnings of the twenty affected subjects are given by:

$$
\tilde{y}_{i}=(1-t) y_{i}+t(1-e) \frac{1}{20} \sum_{j=1}^{20} y_{j}
$$

with $y_{i}$ being individual $i$ 's pre-tax earnings, $t$ being the tax rate chosen by the decisive individual, and $e$ the dead weight loss associated with the tax. The (expected) payoff of the outsider or decisive individual is given by:

$$
\tilde{y}_{d}=y_{d}-c(10 \cdot t)
$$

with $y_{d}$ being his or her base-payoff, $t$ his preferred tax rate, and $c$ the cost of each $10 \%$ tax. Participants were informed that the base payoff of the decisive individual would be randomly drawn from the interval between $\$ 19.80$ (the mean pre-tax payoff of the other 20 subjects) and $\$ 21.80 .^{3}$ Therefore, the final payoff of the decisive individual was either entirely unaffected by taxes and transfers (when $c=\$ 0$, our pure "disinterested observer" benchmark), or else was affected only by the cost of the tax he would choose to impose ("modified disinterested observer" scenario).

Both the tax cost and the efficiency loss parameters were held constant during a given session, allowing their effects to be measured only by between-subject comparisons. ${ }^{4}$ The effects of taxation were explained to subjects verbally, graphically, using a table (Table 1), and by means of an equation resembling (1), so that both more and less mathematically inclined subjects could understand them. Subjects were required to pass a comprehension test before making any decision.

Prior to making their Part I choice, participants were also informed that the pre-tax earnings distribution would be determined by one of four possible methods: a) randomly ("Random"); b) based on the average income of their place of origin ("Where From," derived from their home ZIP code, or, for subjects from coun-

\footnotetext{
${ }^{2}$ The efficiency loss parameter could be interpreted as a measure of the dead weight loss associated with distortionary taxation, or alternatively, as the cost of administering the tax. The latter interpretation was offered to the subjects.

${ }^{3}$ Although it was impossible to totally eliminate comparisons between his own income and that of the other twenty subjects, we chose a base income at least equal to the group average for the decisive individual with the aim of moderating the salience of such concerns. A higher base income would reduce the likelihood of invidious comparisons with higher earners, but increase the likelihood of guilty comparisons with low earners. The impact of the choice of base income can be explored in future experiments. Subjects were told that the identity of the decisive individual would never be revealed, a measure we adopted to eliminate worry over the social tension that he might feel from anyone unhappy with the chosen $t$. The decisive individual's base income had a random element to make it difficult even for that individual to be sure he had been chosen, again to reduce worries about feelings of tension at the end of the session (this is also the reason why a revision stage was not added in cases in which Part I was randomly selected.). We wanted each subject to focus as much as possible, when choosing tax rates, on the consequences for her and others' earnings, and not on any consequences for their own social interactions with the others at the close of the experiment.

${ }^{4}$ Because each subject already made either eight or twelve tax choices in the session under varied sources of inequality, outsider versus insider conditions, and uncertainty versus certainty of own income, while also performing a number of other tasks, varying tax cost or efficiency within sessions seemed inadvisable.
} 
tries other than the US, from their home country); ${ }^{5}$ c) according to their performance on a general SAT-like knowledge quiz ("Quiz"); d) according to their score on a computer-based game of skill ("Tetris"). ${ }^{6}$ The actual method to be employed would be randomly selected at the end of the experiment. Each subject was asked to choose a tax rate for each of the methods. The four methods were designed to mimic different determinants of economic success in real life (luck, initial conditions, effort and/or ability, respectively) and were used to assess differences in agents' attitude toward redistribution relative to their perception of fairness.

After each subject chose four preferred tax rates for Part I, the nature of Part II was explained, questions were invited, and subjects again took a comprehension test.

Part II was an "involved participant" condition in which each subject was again asked to choose a tax rate for each of the four methods, this time on the understanding that if selected to be the decisive individual, his base payoff would be one of the twenty earnings levels described in Table 1 and his preferred tax rate would be applied to the pre-tax earning distribution among twenty participants, including himself. In this case, another subject was randomly selected to receive $\$ 19.80$ to $\$ 20.80$ and be unaffected by either the redistribution or the tax cost. This section was designed to analyze the effect of involvement on subjects' choices. The tax cost and efficiency loss parameters varied across sessions but did not vary between Part I and II.

Before choosing Part II tax rates, subjects had to pass another comprehension test. They were then asked to report how they expected to rank under the three non-random earnings determination methods, and how confident they were about their guesses. They then chose the tax rates, took the 20 question Quiz, practiced the Tetris game for two minutes, and played the Tetris game for five minutes. After this, a coin was tossed to determine whether payments would be based on Part I or II. If Part II was selected, participants were informed of their actual ranking in each of the four methods and were offered the possibility of revising their tax choice (we will refer to this stage as 'Part III'). This condition removed subjects' uncertainty about their relative position in the pre-tax distribution allowing us to study the effects of self-interest under certainty and with a wider range of costs than in Part I. ${ }^{7}$ Then the earnings-determination method was selected (by the roll of two dice), the decisive individual was chosen (by drawing a code number from a hat), ${ }^{8}$ and the final payoffs were announced.

Before exiting the session, subjects were asked to make a series of choices between earning a dollar with certainty and participating in a lottery with a $50 \%$ probability of earning nothing and a $50 \%$ probability of earning a positive amount which increased from one question to the next ( $\$ 1.80$ in the first choice, $\$ 2.00$ in the second, \$2.33 in the third, \$2.67 in the fourth, and \$3.00 in the last). This is a simple example of the "multiple price list" method of eliciting risk attitudes; see Harrison and Rutstrom, 2008. This section, which was not pre-announced to the subjects, contributed on average an extra $\$ 1.50$ (about 6\%) to total earnings, and was included in order to generate an indicator of subjects' risk aversion. After completing it, subjects answered a series of background questions regarding their gender, area of study, socioeconomic background, political inclination, and views on inequality and taxation, while cash payments were counted out and brought to them in closed envelopes. The timing of the experimental session is summarized in Figure 1. All the instructions are available at: www.brown.edu/Research/IDE/walkthrough.

Overall, sixteen experimental sessions were held, involving a total of 336 Brown University undergraduate

\footnotetext{
${ }^{5}$ This information was collected during the log-in procedure, before subjects knew how it would be used

${ }^{6}$ Subjects were told that the version of Tetris to be played was specially modified to put more and less experienced players on a more equal footing.

${ }^{7}$ Whereas the net cost of taxation to the decisive individual ranges from 0 to $\$ 1$ in Part I, it ranges from $+\$ 9.3$ per $10 \%$ tax for the top earner to $-\$ 2.0$ per $10 \%$ tax for the lowest earner in the revised decision stage. As mentioned in note 3 , there was no revision of tax choices if Part I was chosen.

${ }^{8}$ Although subjects themselves had no way to identify code numbers with individuals, this method was used to help convince subjects that the identity of a decisive individual was indeed being determined randomly.
} 
students from a wide range of disciplines. Table 2 summarizes the number of sessions and subjects organized by the exogenous parameters tax cost and efficiency loss. To check the sensitivity of the results to the subject pool, additional sessions were conducted involving a total of 55 adult non-student subjects recruited from the surrounding community. Results of the analysis of these additional sessions are not reported here, but in general they are not qualitatively different than those with students.

\section{Hypotheses And Predictions}

In order to predict how subjects will behave in the experiment we need to make some assumptions about their utility functions. A general form for subject $i$ 's utility function is:

$$
U_{i}=f\left(\tilde{y}_{1}, \tilde{y}_{2}, \ldots, \tilde{y}_{i}, \ldots, \tilde{y}_{21}\right)
$$

where $\tilde{y}_{j \neq i}$ represent the post-tax earnings of each of the twenty other participants potentially affected by agent $i$ 's decision., and $\tilde{y}_{i}$ represents $i$ 's payoff if he/she is selected as the decisive individual, given by (2).

If individual $i$ is purely self-interested, arguments other than $\tilde{y}_{i}$ can be ignored without loss of predictive power. Under this assumption, we can predict:

$H_{0 a}$ : In the "disinterested observer" scenario (Part I) a purely self-interested individual will never select $t>0$ if the tax cost is strictly positive $(c>0)$. When $c=0$ a purely self-interested agent will be equally likely to select any of the possible tax rates $(0,0.1, \ldots 1)$.

In the "veil of ignorance" condition (Part II under random assignment), agent $i$ 's choice will depend on the values of $c$ (tax cost), and $e$ (efficiency loss), as well as on his degree of risk aversion. The following hypothesis can be formulated:

$H_{1 a}$ : In Part II under random income determination, a purely self-interested agent will never select $t>0$ if he is risk neutral or risk loving, and if $c>0$ and/or $e>0$. Among risk-averse agents who are purely self-interested, the utility-maximizing $t$ is increasing in the degree of risk-aversion and decreasing in $c$ and $e$. For the other three methods in Part II, we predict for purely self-interested subjects:

$H_{2 a}$ : In Part II under the Where From, Tetris, and Quiz methods, subjects confident of their predictions about their relative standing will choose 0\% or 100\% taxation, depending on which maximizes their own expected income. In order to maximize their expected utilities, risk averse subjects lacking confidence in their predictions may select positive tax rates which will be higher the lower the tax cost or efficiency loss, the greater is their degree of risk aversion, the lower is their predicted rank for the method in question, and the lower is their confidence (ability to predict their standing).

Consider now an individual who, due to social preferences, attaches a positive weight to the earnings of other subjects. We are interested in two types of preferences: preferences regarding equality and preferences regarding efficiency.

Assuming that agents' utility increases with equality in the distribution of incomes (e), we can write $h(\mathbf{e})$ as a general function linking utility and equality, with $h^{\prime}>0$ if the subject prefers greater equality. ${ }^{9}$

Abstracting from agents' concern for their own income, preference for aggregate efficiency can be formalized in relation to the average of others' aggregate payoffs. Intuitively, the more efficient redistribution is, the larger will be the total pie to be divided among the remaining $N_{j}$ subjects, ceteris paribus. Thus, the utility

\footnotetext{
${ }^{9}$ The possibility that a subject prefers less equality, especially in cases in which he believes that unequal incomes have been justly earned, will also be considered.
} 
individual $i$ gets from aggregate efficiency can be written as: $g\left(\frac{1}{N_{j}} \sum_{j \neq i} \tilde{y}_{j}\right)$, with $g \mathbf{I} \geq 0 .{ }^{10}$

Formally:

$$
U_{i}=f_{i}\left(\tilde{y}_{i}, x_{i}\right)+h_{m, i}\left(\mathbf{e}, x_{i}\right)+g_{i}\left(\frac{1}{N_{j}} \sum_{j \neq i} \tilde{y}_{j}, x_{i}\right)
$$

Function $f_{i}(\cdot)$ can have varying degrees of concavity, thus incorporating risk aversion, and functions $h_{i}(\cdot)$, and $g_{i}(\cdot)$ can vary across individuals both randomly and in relation to a vector of measurable characteristics $x_{i}$ such as gender, ethnicity, political inclination, and socioeconomic background.

The subscript $m$ in $h_{m, i}$ indicates that $i$ 's desire for equality may depend on what method is used to determine pre-tax earnings. For example $i$ may have a strong desire for income equalization under the Where From method if basing earnings on socioeconomic background is perceived by her as unfair, but a much weaker or possibly no desire to redistribute if pre-tax income has been determined by performing a task.

We propose the following compound hypothesis:

$H_{0 b}$. Both in Part I and Part II (under random income assignment), a subject displaying some level of social preferences may select $t>0$ even if $c>0$.

Several sub-hypotheses can be spelled out:

1. The larger $c$ (tax cost) and $e$ (efficiency loss), the smaller the value of $t$ that will be selected, ceteris paribus.

2. The greater $i$ 's preference for equality under the pre-tax income determination method in question, the larger the value of $t$ the agent will select at every stage, ceteris paribus

3. Agents with similar characteristics $x$ will tend to select similar values of $t$, ceteris paribus.

Concern for equality or efficiency does not imply the absence of simultaneously operating self-interest. For example, in both Part II (for any methods other than Random) and Part III, an agent's tax choice will be affected by his expected rank in the pre-tax income distribution via the $f_{i}(\cdot)$ function. Individuals with higher (lower) expected pre-tax incomes will have a stronger bias toward a low (high) tax. However, concerns for equality and efficiency may have effects countervailing those of self-interest, which will be stronger the closer $i$ 's (expected) rank is to the point at which $\partial y_{i} / \partial t=0$ (e.g. between ranks 7 and 8 , when there is no efficiency loss). Also, since Part II decisions are taken prior to learning one's rank according to the various methods, subjects are expected to prefer higher taxes the greater their lack of confidence in their estimate of their relative performance and the greater their degree of risk aversion. Subjects with (almost) any degree of risk aversion have a self-interested reason to choose a high tax under the Random method, in Part II, if tax cost and efficiency loss are zero (low).

\section{RESUlts}

The following analysis is based on the results of the sixteen experimental sessions in which all participants were undergraduate students. Students from a wide range of disciplines participated in the experiment. Subjects were not drawn from particular courses; hence they were not likely to know each other before the sessions. ${ }^{11}$ The large majority of participants appeared to have no difficulty understanding the instructions and answering the control questions. Accordingly, all subjects took full part, making tax choices for each of the four methods -

\footnotetext{
${ }^{10}$ Here, too, $g \prime<0$ is a possibility, for instance a subject may feel better off the less others earn in comparison to her. We let our data tell us whether subjects value the aggregate earnings of others positively, negatively, or neither.

${ }^{11}$ The 336 subjects were drawn from an undergraduate population numbering about 5700 students at the time of these experiments.
} 
both in Part I and II, and in Part III when this occurred (7 out of 16 sessions). All but one subject also completed the debriefing questions as well as the test for the assessment of risk aversion.

The background questions allowed us to collect information about a number of personal characteristics of the participants. These variables, as well as the risk aversion indicator, ${ }^{12}$ are used in the econometric analysis. The distribution of participants by personal characteristics is presented in Appendix Table 2. The questions used to construct the indicators are also reported in the Appendix.

We next illustrate our key findings by presenting the main descriptive statistics. We then discuss the results of a a set of multiple regressions estimated using data from all experimental sessions. ${ }^{13}$ The dependent variable - the tax rate selected by each subject - is regressed on a set of explanatory variables which includes: tax cost, efficiency loss ${ }^{14}$ method dummies, risk aversion, a gender dummy variable, ethnic dummy variables, political philosophy, home area income, socioeconomic status, and number of economics courses taken.

Considering the significant share of $0 \%$ and $100 \%$ tax choices ${ }^{15}$, in order to address the concern that, if allowed, some subjects may have chosen a tax rate less than $0 \%$ (regressive) or more than $100 \%$, we estimate the regressions using a Tobit model, censored at 0 and 1 . We also estimated the same set of regressions using ordinary least squares (OLS) obtaining very similar results. In what follows, we report the results of the Tobit regressions.

\section{A. The “disinterested observer" scenario: Part I}

Do agents' tax choices suggest the existence of a demand for redistribution among the micro-community of the twenty other participants? The large majority of subjects display such a demand in the sense that, all things being equal, they prefer earnings to be distributed more equally than the status quo, no matter which method is used to determine pre-tax income distribution.Considering all the experimental sessions taken together, in $76.4 \%$ of the cases subjects favored some equalization of earnings $(t>0)$, in $44.2 \%$ of the cases a tax rate of $50 \%$ or higher was chosen, and $14 \%$ of the time subjects decided to fully equalize earnings among other participants. The mean tax rate is $42.4 \%$. In principle this result could be due to the choices of those individuals participating in sessions in which redistribution was free or very cheap. However, when only those sessions with a positive tax cost are considered (12 sessions, 251 participants, 1004 tax choices) we observe a very similar pattern. Furthermore, even restricting the analysis to those sessions in which redistribution was more expensive (tax cost $=\$ 1$ per 10\%) the qualitative result remains the same. A large majority $(69.9 \%)$ of the participants still opted for a positive level of taxation, more than a third (34.8\%) for a tax rate of $50 \%$ or higher, and $7.7 \%$ were willing to pay a full $\$ 10.00$ (approximately half of their expected payoff ${ }^{16}$ ) to equalize earnings among the other participants. This evidence supports hypothesis $H_{0 b}$ against the alternative hypothesis $H_{0 a}$.

Does the existence of widespread support for redistribution imply that agents are not responsive to the cost of taxation? The answer suggested by our Part I data is no. As shown in Figure 2a, participants in sessions characterized by high values of tax cost chose lower levels of taxation than participants in sessions with zero

\footnotetext{
${ }^{12}$ Of the 335 subjects completing these parts, 308 answered the risk-aversion questions consistently and 27 in an inconsistent fashion, that is they rejected a gamble with high expected value but accepted one with lower expected value. To keep the sample as large as possible, we defined a second measure of risk aversion which could be calculated for both consistent and inconsistent responders. To check robustness, we carried out each piece of analysis also for the restricted sample composed by those who replied consistently. Since the results turn out to be quite similar, we present in what follows, the analysis for the larger sample.

${ }^{13}$ In some cases, we restrict our attention to the sample of tax choices for one of the four methods of pre-tax determination (335 observations). Most of the time, however, we use the larger sample obtained by pooling together all of the 1340 observations ( 335 subjects by four choices)

${ }^{14}$ Since subjects's choices were very similar for levels of tax cost other than $\$ 1$ per $10 \%$ (see Figure 2a), in order to simplify the interpretation of the coefficient we use a dummy variable which equals 1 for sessions with tax cost $=\$ 1$, and 0 for the others. Similarly for the efficiency loss parameter, we use a dummy which equals 1 for sessions with efficiency loss $=25 \%$, and 0 for the others (see Figure $2 \mathrm{~b}$ ).

${ }^{15}$ A comprehensive description of the distribution of participants' tax choices in Parts I, II and III is reported in Appendix Table 3.

${ }^{16}$ Excluding the show-up fee of $\$ 5$.
} 
tax cost. The difference is negligible for low levels of tax cost but significant when taxation becomes relatively expensive. ${ }^{17}$ This pattern is consistent with the view that redistribution is a conventional good with demand being downward sloping with respect to the price of taxation.

As for concern with aggregate inefficiency, we find that subjects in the disinterested and modified disinterested observer portion of our experiment chose lower levels of redistribution when taxation involved a higher cost in terms of aggregate payoffs, even when this has no impact on their own expected pay-off. As suggested by Figure $2 b$ and confirmed in Mann-Whitney tests, the effect is significant only when the share of tax revenue lost reaches $25 \%$, the highest value included in our design. ${ }^{18}$

The first column of Table 3 confirms the significant negative impact of tax cost and efficiency loss on Experiment I tax choices using a Tobit regression. Both coefficients have the expected sign, and they remain large and highly statistically significant (1\% level) as additional controls are added in columns (2) through (7). According to these estimates, when tax cost rises to $\$ 1$ per each additional $10 \%$ tax, the preferred tax rate falls by somewhere between 10 and 12 percentage points. This is in line with the average tax falling from $45 \%$, in sessions with 0 tax cost, to $34 \%$, in sessions with tax cost of $\$ 1$. Similarly, when the leakage associated with redistribution rises to $25 \%$, the preferred tax rate falls by between 7 and 9 percentage points, in line with the 8.4\% drop in Figure 2b.

Individual demand for redistribution may also be influenced by beliefs about the determinants of inequality. The set-up of Part I, which lets subjects choose different tax rates for each of the four methods, allows us to study how perception of fairness informs redistributive decisions. If agents are indifferent about how initial income is determined, we should observe no systematic differences in tax choices across different methods. However, we do, in fact, observe such differences. In particular, as depicted in Figure 3 subjects tend to express a greater desire for redistribution when pre-tax earnings are determined according to the Random and the Where From methods (mean tax rates of $49.3 \%$ and $45.1 \%$, respectively) than when relative performances in the Tetris and Quiz games are used (37.7\% and 37.3 respectively). ${ }^{19}$. These differences are confirmed in the regressions of columns (2) through (6) of Table 3, in which we include dummy variables for the Where From, Tetris, and Quiz methods of determining pre-tax earnings. Although preferred tax under the Where From method is never significantly different from that in the default method, Random, the estimates consistently show differences of about $11 \%$, significant at the $1 \%$ level, for the preferred redistributive tax when earnings are determined by performance in a quiz or computer game. These results are in line with others suggesting that aversion to inequality and demand for redistribution may crucially depend on agents' beliefs about what causes one to be rich or poor, and, in general, about how fair the process is that generates the pre-tax income distribution.

In columns (3) - (5) of Table 3 we test for possible influences of sets of personal characteristics. Column (3)'s regression suggests that female subjects wanted as much as $13 \%$ more of others' incomes to be redistributed than did male subjects, whereas there are no significant differences in demand for redistribution based on ethnicity. Column (4)'s estimate suggests that the average income of the subjects' home area is negatively correlated with the demand for reducing inequality among others, while more risk averse subjects preferred more equality among others' incomes. Column (5)'s estimate indicates that subjects self-reporting more po-

\footnotetext{
${ }^{17}$ A series of Mann-Whitney tests find no significant difference in the preferred tax between subjects facing $\$ 0$ up to $\$ 0.5$ cost per $10 \%$ tax, but do find tax choices to be significantly lower at \$1 tax cost than at lower levels (significant at the 5\% level in two-tailed tests).

${ }^{18}$ Recall that in the case of complete equalization, a $25 \%$ efficiency loss means that a fourth of the total pie is foregone. Two-tailed MannWhitney tests show no significant difference in preferred tax between the $0 \%$ and $12.5 \%$ efficiency loss sessions, but a lower preferred tax at $25 \%$ efficiency loss than at $12.5 \%$, significant at the $10 \%$ level, and at $25 \%$ versus $0 \%$ efficiency loss, significant at the $5 \%$ level.

${ }^{19}$ To make sure these differences are not driven by a relatively small number of extreme observations, we perform a series of Wilcoxon matched pair tests for within-subject comparisons. The tests confirm our main finding, showing that subjects were somewhat more likely to choose a higher tax for the Random than for the Where From method (p-value: .021), and much more likely to choose a higher tax for both the Random or Where From methods than for the Quiz or Tetris ones (p-values below 0.001 in all four comparisons). Finally, we find no evidence of significant differences in preferences between the Tetris and Quiz methods (p-value: .276).
} 
litically liberal views preferred more redistributive taxation, while those who took more economics courses preferred less. Column (6) shows that each of these results is robust to the inclusion of all of the variables in the previous columns' specifications, and column (7)'s regression shows that this remains the case if the pre-tax income determination method is controlled for by only the combined dummy variable Tetris-Quiz.

In sum, in the disinterested and modified disinterested observer decisions (Part I), subjects wanted less redistribution when the direct cost to them or the losses to others through tax leakage were higher and when pretax incomes were performance-based, and subjects from higher-income areas and those taking more economics courses also preferred significantly less redistribution. Subjects who were female, more risk averse, and more politically liberal preferred significantly more redistribution.

Some of these results are relatively familiar and increase confidence in the "normalcy" of the subject pool and the possible external validity of the experiment. For example, responsiveness to Tax Cost suggests that there is a downward sloping demand for redistribution, while the significant correlation of demanded redistribution and self-reported liberalism helps us to argue against the notion that choices in our experiment may have no relation to the kinds of preferences expressed in the political sphere. The higher preference for redistribution among women than among men may be related to previous experimental evidence that women tend to be more altruistic than men (Eckel and Grossman, 1998), and it also accords with evidence of the gender gap in voting on social issues in the United States (Kaufmann and Petrocik, 1999; Norrander and Wilcox, 2008). The desire of many subjects to tamper less with incomes that have in some sense been "earned" resembles results found elsewhere (e.g. Hoffman and Spitzer, 1985).

Some of the findings deserve additional comment in view of the fact that the decision-maker in Part I is (for the most part) an outsider given the opportunity to alter income distribution among others, not an involved participant. First, the preference for about $8 \%$ less taxation when a quarter of tax proceeds would be lost on administrative leakage indicates that on average subjects do care about efficiency (Charness and Rabin, 2000) and not only about equalizing incomes or raising up those of the lowest earners. Second, the impact of home area income on preferred tax cannot be understood in terms of pure self-interest but must rather be seen as suggesting a taste, possibly sprouted in the soil of self-interest but carried over to a domain in which selfinterest has no direct application (high income individuals simply view redistribution less favorably). Similarly, the impact of risk aversion on a decision that has no bearing on the protection of own earnings suggests a perhaps durable correlation of tastes. In particular, whereas the more risk-averse are expected to prefer more redistribution to protect their own earnings, in Part II, the Part I result suggests that those who prefer to bear less risk, personally, also happen to like equality of earnings among others, even if one preference in no way logically entails the other. ${ }^{20}$

The strong effect of gender also calls for further unpacking. Upon further examination, one of the most interesting features of our data turns out to be that virtually all of the difference between male and female preferences for redistribution found in Table 3 can be attributed to the different ways in which male and female subjects react to the source of income, the direct cost of redistribution, and redistribution's efficiency cost. The first of these effects is the strongest and is displayed graphically in Figure 4, which shows that whereas males tended to have a substantially lower demand for redistribution when the inequalities derive from performance, this was much less true of females. Differences in the effects of tax cost and efficiency loss can be similarly illustrated but are not shown due to space limitation.

\footnotetext{
${ }^{20}$ The possibility that more risk-averse subjects may have chosen higher taxes in Part I because they did not understand their own earnings to be unaffected-in other words, that they confused Part I with Part II - is ruled out by the fact that subjects did not know the Part II task when making their Part I tax choices, and that all subjects correctly answered questions showing their comprehension of Part I prior to entering their tax decisions.
} 
We study further how gender affected tax choice through its interactions with the factors just mentioned using the series of regressions in Table 4, which also control for the the other individual characteristics included in Table 3's main specification. Column (1) provides a basic specification with only Tax Cost, Efficiency Loss, the Tetris-Quiz methods dummy and the female gender dummy, all showing much the same significant coefficient values as in Table 3. In column (2), inclusion of an interaction term between the female and TetrisQuiz dummy variables causes the female dummy's value to decline by roughly a half and its significance level to fall to only $10 \%$. In column (3), we include instead an interaction term between the female and Tax Cost variables, and in column (4), an interaction between female and Efficiency Loss. Inclusion of these interaction terms reduces the estimated coefficients on the stand-alone female dummy variable and their significance levels more modestly, and the interaction terms themselves obtain positive coefficients significant at the $10 \%$ (column (3)) and 5\% (column (4)) levels. Finally, in the specification of column (5), all three interaction terms are included and each obtains the same significance level as in its respective column (2), (3) or (4) specification. Now, however, the coefficient on the stand-alone female dummy variable is less than a tenth of its original magnitude and its estimate is not remotely significant. Together, these results suggest that the effect of gender on desired redistribution is accounted for by the fact that female subjects are considerably less deterred from redistributing by incomes being earned in a quiz or Tetris game, the fact that female subjects reduce their redistributive choice less than males as the direct cost to them rises, and by the fact that female subjects are much less deterred from redistributing by the presence of substantial transfer inefficiency than males. ${ }^{21}$

\section{B. The "involved observer" under uncertainty: Part II}

In Part II of the experiment respondents were invited to select a tax rate for each of the four earnings assignment methods, knowing that if selected, their preferred tax would be applied to the earning distribution among twenty participants, this time including themselves. When making their choice, individuals were uncertain about which position they would eventually occupy in the distribution of payoffs.

When directly affected by redistribution, agents' choices can be expected to be influenced by self-interest considerations, in addition to any fairness concerns evident in their Part I decisions. Under the Where From, Tetris and Quiz methods, subjects could form expectations of their possible pre-tax earnings rank and take these into account when deciding how much to redistribute. If confident enough about their guess, subjects with relatively low expected rank (that is, high predicted pre-tax earnings) would have an interest in choosing a low tax rate, and conversely for those anticipating a high rank. However, uncertainty about earnings rank, including the radical uncertainty under the Random condition, provides a motive for favoring redistribution if the individual is risk averse. Finally, individual tax choice could also reflect agents' social preferences and aversion to inequality (if any).

The regressions in Table 5 explore similarities and differences in tax choices under the Random method in Part I and II, pooling together the 335 observations for this condition in each Part. As before. we control for Tax Cost and Efficiency Loss (which vary across sessions) and for our risk aversion measure, gender, home area income, political philosophy response, and number of economics courses. Each variable obtains a significant coefficient of the same sign and similar magnitude to Table 3, except that the coefficient on the Female dummy variable is quite insignificant. In column (2), we add a dummy variable to identify the observations from Part II, and this obtains a positive and significant coefficient indicating that on average subjects' tax choices were

\footnotetext{
${ }^{21}$ The coefficients in column (5) indicate that the average female subject reduced preferred tax by only $4 \%$ versus $14 \%$ for male subjects, in response to a shift to Quiz or Tetris income determination, that such a subject reduced redistribution by only about $5 \%$ versus a male subject's $14 \%$ reduction when Tax Cost rose to $\$ 1$ per $10 \%$ redistributed, and that she would reduce redistribution by only a little over $1 \%$ versus a male subject's reduction by over $11 \%$ in response to Efficiency Loss rising from 0 to $25 \%$.
} 
about 6\% higher in this part, a change in the predicted direction given that there is now an added motivation to redistribute assuming self-interest coupled with risk aversion.

One way to check whether the preference for more redistribution under the Random method in Part II is due to risk aversion, as is predicted by theory, is to interact the Part II dummy with our risk aversion measure (Table 5, column 3). If the measure performs well and if risk aversion is a driver of the desire to redistribute, the coefficient on the interaction term should be positive and significant. Surprisingly, it is neither. This finding, is not necessarily devastating to the theory, since risk aversion is notoriously difficult to measure. Other coefficients, including the significant positive coefficient on the risk aversion level term, remain unaffected.

We now turn to the issue of whether, and to what extent, demand for redistribution is influenced by the expectation about what position one will occupy in society in the future. We can address this question by looking at the difference between choices in Part I and Part II for methods other than the Random one.

Overall average tax rates for the three other methods appear to be very similar between Part I and Part II. For the Where From method the average tax in Part I and II are essentially the same (45.1\%); for the Tetris method the difference is less than 1 percentage point (37.7\% in Part I, and 36.8\% in Part II), and for the Quiz method about $2.6 \%$ (37.3\% in Part I against 39.9\% in Part II).

However, this result hides important variations at the individual level. In fact, almost half of the subjects change their preferred tax choice in Part II relative to Part I, although these changes are generally small (around 20\%). This pattern holds for all methods, with a slight tendency for larger changes in the Where From method. The proportion of participants who choose a higher tax is similar to the share of those choosing a lower tax, both ranging around $20 \%$.

In Table 6, we report a series of Tobit regressions on only the Part II tax choices under Where From, Quiz, and Tetris-based determination of pre-tax incomes. As depicted in column 1, most of the results that hold for Part I decisions continue to hold for those of Part II. In particular, average tax rates decrease with tax cost and efficiency loss; female, liberal, and more risk averse individuals tend to support more redistribution than male, conservative and less risk averse subjects; preferred tax continues to be negatively correlated with the level of home area income. ${ }^{22}$ Only the coefficient on the number of economics courses taken, which is still negative, loses the significance displayed in Table 3.

That the same factors which predict voting for redistribution in Part I operate in the same manner and explain a similar proportion of the variance in votes for redistribution in Part II suggests that preferences for greater equality operated in a similar fashion whether the decision-maker was an interested party or not. ${ }^{23}$ The regression in column 2 allows us to explore how important these factors are in comparison with the immediate self-interest of the decision-maker. This regression adds the subject's self-reported expected rank to the set of independent variables. Subjects with a high expected rank (low expected pre-tax earnings) could increase their expected earnings by voting for a high level of redistributive taxation, while those with low expected rank expected to earn more with no taxation. This expectation is strongly born out by the distribution of tax choices in Figure 5 which displays a gradual shift towards more redistribution going from high to low expected rankings. The estimate in column (2) of Table 6 confirms that self-interest played this role: the coefficient on expected rank is positive and significant at the $1 \%$ level. The explanatory power of the regression also rises dramatically, more than doubling according to the Psuedo R-square. By this measure, self-interest is at least somewhat more important than pure preferences about equality when subjects chose taxes in our experiment

\footnotetext{
${ }^{22}$ As in Part I, also in Part II the result on the income variable is driven by the tax choices for the Where From method. When the other two methods are considered the income variable has essentially no predictive power.

${ }^{23}$ Another way of demonstrating this is to regress the subject's tax choice in Part II for a given method on their tax choice in Part I for the same method. When this is done, the coefficient on Part I tax choice is positive and statistically significant at the $1 \%$ level.
} 
from behind a partial veil of ignorance.

The remaining specifications shown in Table 6 take into account variation in a subject's confidence regarding her prediction of pre-tax earnings rank. In column 3, we add a dummy variable, Confidence, set to 1 for subjects who reported being very confident about their prediction of rank and 0 for those who reported being "somewhat" or "not at all confident." ${ }^{24}$ We also add an interaction term between Confidence and Expected Rank. As expected, Confidence has a negative effect on the chosen tax: the less confident is the subject in his or her prediction, the more does the situation resemble the Random case, in which a risk-averse individual will prefer more redistributive taxation, ceteris paribus. The interaction term is significant and positive in line with the prediction that a subject more confident of having a high pre-tax rank number (low pre-tax earnings) will want greater redistribution. Appendix Figure 1 provides a graphical representation of these result based on the regression coefficients.

In columns (4) and (5) we introduce an interaction with an indicator for the methods Tetris and Quiz. In Part II as in Part I, subjects chose less redistribution under these methods, but perhaps this is partly due to greater confidence in their predictions of their earnings rank in the Where From than in the Tetris and Quiz cases. ${ }^{25}$ The significant negative coefficient on the interaction between the Tetris-Quiz dummy and Expected Rank, in columns (4) and (5), is consistent with this idea: under these two methods, there is less demand for redistribution by those whose guesses about their own rank, held less confidently, would otherwise tend to make redistribution desirable. The negative coefficients on the Tetris-Quiz dummy itself are also replaced by positive ones, apparently because these pre-tax earnings determination methods mainly proxy for uncertainty once their interaction with expected rank has been controlled for. The effects found in column (4) remain when the Confidence*Expected Rank interaction is once again included, in column (5).

\section{The "involved observer" under perfect information: Part III}

The revised decisions in Part III, made after the revelation of exact rank under each of the four methods, provide evidence on subjects' distributive preferences and on the weight they place on them relative to own earnings in the absence of uncertainty and over a substantially wider range of private costs than in Part I. Risk aversion has no direct relevance in this case, and in principle, a purely self-interested subject should choose either a $100 \%$ tax or a $0 \%$ tax, depending on his revealed rank under each particular method. ${ }^{26} \mathrm{~A}$ deviation toward redistribution by those whose earnings would be maximized by a $0 \%$ tax must reflect concern for lower earners or a preference for equality. By contrast, downward deviations by subjects whose self-interest favors a $100 \%$ tax could be motivated by a belief that the higher incomes are rightfully earned or deserved or by some other source of reluctance to alter the unequal earnings pattern.

Overall, 147 subjects in 7 experimental sessions were offered the opportunity to revise their initial tax choice in each of the four methods (for a total of 588 observations). In addition to the usual tax cost, when revising their preferred tax, individuals took into account their potential additional payoff from redistribution. This was positive if their ranking was such that they would benefit from taxation, or negative, otherwise. ${ }^{27}$

\footnotetext{
${ }^{24}$ With regard to the expected rank participants could select one of the following options: "Positions 1-2" (where 1 is the highest income); "Positions 3-5"; "Positions 6-8" ; "Positions 9-11"; "Positions 12-14"; "Positions 15-17"; "Positions 18-20". With regard to the level of confidence, three options were available: "Very confident"; "Somewhat confident"; "Not at all confident".

${ }^{25}$ Subjects can form good estimates of the relative level of their home area income, but had less basis for guessing their relative performance on tasks they had not yet performed. The data show their guesses of earnings rank to be substantially more accurate for the Where From than for the other two methods; their self-reported confidence in their guesses was also higher.

${ }^{26}$ Unlike some previous studies (e.g. Herne and Suojanen, 2004) in our experiment participants are not allowed to communicate after having learned their actual position in the distribution. Furthermore, when making his/her revised tax choices each subject had in hand a printed copy of Table 2, or of the variant appropriate to the relevant efficiency loss.

${ }^{27}$ In sessions with no efficiency loss, for example, redistribution harms the decisive individual if he is ranked between the 1 st and the 7 th position when tax cost is zero, between the 1st and the 8th position, when tax cost is $\$ 0.25$, between the 1st and 12 th position when
} 
Altogether, 53.7\% of the observations are of subjects facing methods in which their own earnings would be maximized with a tax of $100 \%$, while for the remaining $46.3 \%$ of observations own income would be maximized by a tax of $0 \%$.

Although agents had no difficulty in recognizing and pursuing what was in their interest, about one third of choices $(34.2 \%)$ were for a tax rate that did not maximize the chooser's earnings, and $61.2 \%$ of subjects selected such a tax rate in at least one of their choices. ${ }^{28}$

The numbers and sizes of deviations from an income-maximizing tax of $0 \%$ and those from an income maximizing tax of $100 \%$ are similar with the average deviation being about $18 \%$ and with slightly more and larger deviations in the upward (pro-equality) than in the downward direction.

It is worth noting that among subjects with the same income-maximizing tax, the cost of taxation varied significantly depending on the exact rank. Intuitively, the cost of redistribution in terms of foregone earnings for someone at the top of the ranking is higher than for someone ranked 2nd, and so on. Similarly, the net benefit from redistribution for someone ranked 20th is higher than for someone ranked 19th and so on. To account for this, we calculated the net cost of a 10\% increase in tax for each income rank, tax cost, and efficiency loss. For example, someone ranked 1 st in a session with zero efficiency loss and $\$ 1$ tax cost, would sacrifice about $\$ 9$ of his potential payoff per each additional $10 \%$ tax he would impose if selected to be decisive. By contrast, in the same session, someone ranked 9th would still have a positive incentive to choose a zero tax, but deviation would only cost him about 65 cents per $10 \%$ tax. Similarly, for subjects who would potentially benefit from redistribution, low ranked participants had a much greater incentive to choose a $100 \%$ tax than subject ranked toward the middle. Due to this, the cost of redistribution to the decisive individual covers a much larger range in Part III than in Part I, allowing observations on willingness to pay for redistribution at costs both well above the Part I maximum tax cost of $\$ 1$ per 10\% and well below the Part I minimum tax cost of $\$ 0$ per $10 \%$ tax.

Figure 6 reports for each positive or negative total cost per 10\% tax increase the average tax selected by subjects in Part III. ${ }^{29}$ As expected, those individuals who, given their revealed ranking, should choose a zero tax rate (net losers) generally support low levels of redistribution. Furthermore, pro-redistribution deviations from self-interest are decreasing in the cost of taxation. In other words, when their position in the pre-tax earnings distribution is high and deviating is very costly in terms of foregone earnings, subjects choose a tax rate very close to 0 . However, when deviating from the purely selfish option becomes sufficiently cheap, individuals tend to support higher levels of redistribution and their choices are fairly responsive to variations in the cost of taxation. ${ }^{30}$ This pattern is intuitive and certainly reassuring of the fact that subjects had a good understanding of the experiment and a relatively clear perception of the incentives they faced.

Turning to the left part of the Figure 6, to those subjects who, based on their rank, would benefit from redistribution (net winners) and should hence choose complete equalization, we can see that the large majority of these selected a very high tax rate (70\% or higher), and about two thirds chose to fully equalize earnings (average tax rate $82.5 \%$, standard deviation 0.30 ). The scatter of points suggests some modest responsiveness to the size of the loss suffered by not selecting full redistribution, but we will see shortly that the relationship is much flatter than that for costs in the positive range. Nonetheless, enough subjects resist full redistribution,

tax cost is $\$ 1$. The cut-off point is between the 14 th and the 15 th position when efficiency loss is $12.5 \%$ and tax cost is $\$ 1$, between the 9 th and the 10th position when efficiency loss is $25 \%$ and tax cost is $\$ 0$ and between the 11th and the 12th position when efficiency loss is $25 \%$ and tax cost is $\$ 0.25$

${ }^{28}$ This proportion is high compared with the findings of previous experiments involving no income uncertainty and no strategic considerations, such as Rutstrom and Williams (2000). This might be explained in part by subjects' desires for self-consistency and by the fact that Part III came after parts I and II.

${ }^{29}$ Costs on the tails of the distribution are not shown to permit closer inspection of the main part of the data. $4.7 \%$ of the observations lie in the ranges thus excluded.

${ }^{30}$ When the net cost of taxation is between $\$ 0$ and $\$ 1$ per $10 \%$, the average tax rate is $37 \%$, similar to the average tax choice in Part I $(42.3 \%)$. 
when in their own interest, to suggest that it's not the case that subjects are either strictly self-interested or else egalitarian. Some subjects, in some circumstances, are willing to sacrifice personal earnings to maintain some inequalities (and, when $e>0$, to avoid shrinking the pie by redistribution).

In Table 7 we estimate a regression model for Part III tax choices as a function of the total cost of taxation to the decision-maker (per 10\% tax), the square of that cost, a dummy variable "earnings maximizing tax rate" (EMTR) which is either $1(100 \%)$ or 0, and the interaction between EMTR and total cost of taxation.

As expected, tax choices appear to be very sensitive to the net cost of taxation faced by each subject (both the coefficients on cost of taxation and its square term have the expected sign and are statistically significant). However, the fact of having a net gain from redistribution has an independent, strong and positive impact on preferred tax rate.

Indeed, the coefficient on the interaction term between EMTR and the cost of taxation suggests that a change in the total cost (benefit) of taxation has a significant impact only on those subjects with an earningsmaximizing tax of 0 , but has essentially no effect on the choices of net winners.

How do preferences for equality affect individuals' redistributive choices when uncertainty is resolved? In principle we would expect individuals with more egalitarian views to be, on the one hand, more inclined to deviate from the purely self-interested zero tax choice, and, on the other, less likely to deviate from $100 \%$ tax choice when this is in their interest.

One way to test this prediction is by using the tax rate chosen by the same individual for the same method under the "disinterested observer" condition (Part I) as an indicator of the subject's genuine "disinterested" attitude toward equality. To do so in column 2 we include in the initial specification the variable "Part I Tax" corresponding to the tax rate chosen by the same subject for the same method in Part I. In line with our prediction, the coefficient on the Part I tax choice is positive and statistically significant. This result confirms that participants who selected higher taxes in Part I tend to support more redistribution than others in Part III, and this regardless of their actual ranking and of the cost they face.

Figure 7 shows the relationship between selected tax rate and total cost of taxation, according to the coefficients in column 1 of Table 7. Figure 8 plots the relationships separately for subjects choosing high and low tax rates in Part I (higher or equal, and lower than $50 \%$ respectively) ${ }^{31}$ It is worth noting again that the predicted tax choice in Part III when the cost is zero is quite close to that in Part I, suggesting that Part III choices indeed help us to extend Part I conclusions to a broader set of both positive and negative costs of taxation to the decisive individual. ${ }^{32}$ Also worth noting are the sharp discontinuity between the positive and negative cost sides of the figures, and the considerably gentler slope of the curves to the left, indicating lesser sensitivity to cost. Finally, the fact that the average tax remains below $100 \%$ even when in the self-interest of the decision-maker suggests that some inequalities had legitimacy.

\section{WHAT LEVEL OF REDISTRIBUTION MAXIMIZES SOCIAL WELFARE?}

To what extent should fiscal redistribution in a politically democratic industrial market economy be understood as increasing welfare quite generally, due to a desire for income insurance or a social preference for greater equality, versus representing the self-interested expropriation of a richer minority by the poor and middle income majority?

If there is unanimous agreement (even among those with higher pre-tax incomes) that income should be

\footnotetext{
${ }^{31}$ These estimates are based on the coefficient of a separate regression, analogous to the one in Table 7 column (2), in which, instead of the actual Part I tax rate, we include a dummy variable which equals one for those subjects who chose a tax rate of $50 \%$ or higher for the same method in Part I, and 0 otherwise.

${ }^{32}$ The fact that for very high tax costs, the estimated curves imply a preference for negative rates of taxation is an artifact of the specification of Table 7's regressions, which do not explicitly impose the lower limit actually faced by our subjects.
} 
distributed more equally, then taxing and redistributing income can be Pareto-improving. But if a majority favors some redistribution and a minority prefers that there be none, as in our results, then to say whether "society" is better off redistributing, and how much redistribution is best, requires some way of aggregating the well-being of different individuals.

To illustrate, we conduct an exercise which posits a specific cardinal form of utility function that can be calibrated from our data to determine what level of redistribution maximizes additive (Benthamite) social welfare. In our exercises, we assume that each individual's utility is a function of:

1. her expected post-tax earnings;

2. the (expected) variance of her earnings (a measure of the income uncertainty to which she is exposed);

3. the degree of income inequality in the overall population;

4. the aggregate earnings of the population.

For simplicity, we suppress consideration of the individual characteristics $x_{i}$ that were included in equation (4), and we decompose function $f_{i}$ of that equation into additively separable functions of $i$ 's income and its variance. Factors (3) and (4) are assumed to be only functions of the vector of income for the twenty individuals whose earnings are determined by the tax rate chosen by the decisive individual. We use a simple statistic, one minus the Gini coefficient, to capture the degree of equality in the income distribution, and we assume that the function $g_{i}\left(\sum \tilde{y}_{j}\right)$ of equation (4) takes the multiplicative form $\delta_{i} \bar{y}$, where $\delta$ is a scalar and $\bar{y}$ the average income. Then the utility function can be written as:

$$
U_{i}=E\left(y_{i}\right)+\beta_{i}\left(\sigma_{y_{i}}\right)+\psi_{i} h(1-G i n i)+\delta_{i} \bar{y}
$$

To facilitate the recovery of the parameters of function $U$, we assume function $h$ to have a quadratic form: $h(1-$ Gini $)=a+b(1-$ Gini $)+c(1-\text { Gini })^{2}$

After multiplying and renaming the coefficients and dropping the constant, we can rewrite the utility function as follows:

$$
U_{i}=E\left(y_{i}\right)+\beta_{i}\left(\sigma_{y_{i}}\right)+\gamma_{i}(1-\text { Gini })+\eta_{i}(1-G i n i)^{2}+\delta_{i} \bar{y}
$$

Under the assumption that subjects choose the tax rate that maximizes their utility under each experimental condition, we can use our experimental data to estimate the parameters of the utility function. While the form of the utility function is assumed to be common across all subjects, the parameters of (5) are allowed to vary with specific individual characteristics such as risk aversion, political ideology, and concern for efficiency. ${ }^{33}$

The estimation model differs somewhat when analyzing tax choices performed in part I, in part II (under random and non-random methods respectively), and part III. For example, since the decisive individual faces no income uncertainty in both part I and III, $\beta$ - the coefficient on income variance -cannot be estimated from tax choices made under those conditions. Similarly, the estimating equations for parts II and III take into account the fact that the payoff of the decisive individual depends on her expected or actual rank, whereas rank is irrelevant to her payoff in Part I.

Finally, while in principle we view each subject as having a unitary utility function that responds differently to different conditions, it is convenient to capture differences in response to inequalities having different origins

\footnotetext{
${ }^{33}$ More precisely we allow income variance to matter more for subjects with higher measured risk-aversion, concern for equality to be greater for subjects with more liberal political ideology, and finally concern for redistributive efficiency to be larger for participants having taken more economics courses, but we allow the degree of influence of these concerns, if any, to be established by the data.
} 
by estimating utility function parameters separately based on the tax choices made under each method. We also carry out estimates with the combined data of Part I, for reference purposes.

Leaving the details of the derivation for the Appendix, in Table 8 we show the implied signs of parameters $\beta, \gamma, \eta$ and $\delta$ for each of the four subsets of our data, as well as the significance levels of the coefficients on which each parameter estimate is based. ${ }^{34}$

The results support the idea that most subjects are concerned with inequality, and that their utilities display some level of concavity in our Gini-based equality measure: all coefficients on which the estimates of $\gamma$ and $\eta$ are based, are statistically significant at the $1 \%$ level and have signs and numerical values consistent with substantial concavity in the relevant range. Results for $\delta$, the coefficient on aggregate income, are supportive of the expectation that efficiency matters in Part I and Part II Random choices, but have a sign opposite than expected and are statistically insignificant in the other two estimates. The key coefficient for estimating $\beta$, the coefficient on own income uncertainty, is insignificant for both Part II estimates.

The concavity of the utility functions with respect to equality implies that for most subjects utility reaches a maximum at an interior value of $t$. The four panels of Figure 9 illustrate the relationship between utility and $t$ for different population subsets and income determination methods based on Part I tax choices. Panel (a) shows the average relationship between utility and $t$ for those subjects who self-reported to be very conservative (response 1 on the 1-7 political ideology scale), while panel (b) shows the corresponding relationship for very liberal ones (response 7). ${ }^{35}$. We also estimated the utility function parameters separately for each income determination method. In panel (c) we show the relationship between utility and tax rate for a subject with average ideology under the Random method, and in panel (d), the corresponding relationship under the Quiz method. For an individual with average political ideology the optimal tax rate is $30 \%$ when the pre-tax income is determined randomly, and $40 \%$ when it is determined according to the performance in the quiz.

With the utility function estimates in hand, we can now calculate the value of $t$ that maximizes the sum of subjects' utilities under various conditions. For example, basing the utility function estimate on all tax choices in Part I - without regard to determinant of initial income - the tax rate that maximizes the sum of utilities is $43.0 \%$. If we only use the tax choices under the Random income determination method, the tax maximizing the sum of utilities is $52.3 \%$, versus a rate of only $37.7 \%$ based on tax choices for the Tetris method. Using tax choices by involved observers in the Random income condition of Part II, the tax rate maximizing the sum of utilities is $55.5 \% .^{36}$ Thus, even when not personally affected by the outcome, our subjects' summed welfare appears higher when substantial redistribution occurs, especially when income differences don't seem to be earned. The additional effect of self-involvement (the shift to Part II) is not large.

How do our subjects' tastes for redistribution compare to the amount of redistribution delivered by the realworld political process? Actual redistribution of income through the U.S. fiscal system does not conform to potential outcomes in the experiment, because federal income taxes have a progressive rather than proportionate structure, much revenue is generated by other federal, state and local taxes, only a fraction of the revenue collected goes into transfer payments, some progressivity-imparting transfers are income-tested, various exemptions apply, and so forth. Nevertheless, we can get an impression of how the apparent preferences of our

\footnotetext{
${ }^{34}$ As shown in the Appendix, the imputed value of $\eta$ is based on the estimate of one coefficient only, while the values of $\beta, \gamma$ and $\delta$ are based on the joint estimation of that and another coefficient. Since the coefficient from which we recover the value of $\eta$ turns out to be highly significant in all cases, we report in the columns for $\beta, \gamma$ and $\delta$ only the significance levels for the other relevant coefficient in each case.

${ }^{35}$ The utility levels displayed in Figure 9 are calculated assuming $\mathrm{c}=1$ and $\mathrm{e}=.25$, and for an average number of economics courses taken (approximately 1.3). The exercise abstracts from the disutility due to risk born by the decisive individual but unrelated to the chosen $t$.

${ }^{36}$ The sum of utilities based on the Where From condition and the Quiz condition choices achieve their maximum with $\mathrm{t}=45.9 \%$ and $\mathrm{t}$ $=38.1 \%$, respectively.
} 
subjects relate to the degree of redistribution observed in the U.S. and other industrialized countries by comparing before- and after-tax-and-transfer (for convenience, we'll say more simply "pre- and post-tax") inequality in the experiment to that observed at the macro level. Our experiment imposes the same pre-tax inequality on subjects as was actually observed in the U.S. The associated Gini coefficient is 0.51 . The median preferred taxes in experiments I, II and III - 40\%, 40\% and 60\%, respectively - would bring the Gini coefficient down to $0.306,0.306$ and $0.204 .{ }^{37}$ These outcomes can be compared to the actual post-tax Gini coefficient for U.S. individuals in 2000, 0.401 .

Comparison with the degrees of redistribution inferred from the experiment data suggest that our subjects may be somewhat unrepresentative of the overall U.S. population, that choices made in the context of our laboratory experiment are not perfect proxies for the preferences voters have in mind when they go to the polls, or that the political process does not generate outcomes that perfectly match median preferences. One reason may be that the high level of redistribution preferred in Part III, especially, reflects mainly the self-interest of most individuals in redistribution given the right skewed distribution of pre-tax incomes, but may exaggerate interest in redistribution in a more realistic setting because real world voters may take into consideration dynamic (incentive) effects of taxation that are lacking in our experiment. Nevertheless, our subjects' preferences do not seem to be completely "off the map" for voters in industrial democracies, since their desired post-tax Gini coefficients are for most conditions slightly larger than those in very egalitarian countries such as Denmark (Gini=0.220) or Sweden $(0.261){ }^{38}$

\section{Vi. Conclusions}

What is the relative importance of social preferences for equality as opposed to other forces such as self-interest and risk aversion in determining support for redistribution at the societal level? Does demand for redistribution vary with the perception of whether earnings are 'deserved' or not?

To address these questions, we conducted sixteen experimental sessions in each of which each of twentyone subjects could potentially determine the degree, if any, to which an array of earnings mirroring U.S. pre-tax income distribution would be modified by a linear tax-and-transfer scheme under earned and unearned income conditions as well as in both the situation of a disinterested observer and that of an involved observer, the latter both under uncertainty about own position and after resolution of uncertainty. Our experiment is distinctive in its combination of large groups, large subject pool, macro framing, decision-making under multiple conditions, and variation of both direct cost to decision-maker and efficiency cost of redistribution. While participants were mainly undergraduates at Brown University, a smaller set of parallel sessions obtained similar results for non-student adult subjects.

Both the median selected tax rates and the tax rates maximizing the sum of calibrated utility functions (aggregate social welfare) call for the elimination of about half of pre-tax income inequality when the efficiency loss is low or zero. Self-interest stands out as a dominant concern in the interested decision-maker conditions, with most choices converging toward the degree of redistribution maximizing own income when uncertainty of position is resolved and with high redistribution levels being a natural outcome of the right-skewed nature of the pre-tax distribution. Yet preferred redistribution levels were only a few percent lower in the disinterested observer condition. Because the situation in which voters find themselves when voting on candidates who will determine tax and transfer levels resembles more that of our involved observer conditions, with some degree of uncertainty but also some knowledge of position, our findings suggest that self-interest, including risk-aversion,

\footnotetext{
${ }^{37}$ The tax levels that would maximize the social welfare function as discussed above, $37.7 \%$ for the Tetris method and $52.3 \%$ for the Random method, correspond to Gini coefficients of 0.318 , and 0.243 respectively.

${ }^{38}$ Gini coefficients for disposable income in 2001, from the United Nations World Income Inequality Database
} 
suffices in practice to explain most of the observed preference for reducing inequalities by state action. But our data also suggest that disinterested social preferences for equality would lead to only slightly lower levels of redistribution, were concerns about the impact on own earnings not present.

Turning to the second question with which we began this section, our subjects' choices suggested a considerable impact of whether relative pre-tax earnings were or were not determined by knowledge or skill, with the average preferred level of taxation and redistribution being about $27 \%$ greater in "earned" than in "unearned" income conditions. ${ }^{39}$ Our findings are consistent with the suggestions of authors like Benabou and Tirole (2006) that differences in demand for redistribution across countries may be explained, at least in part, by different beliefs about the extent to which pre-tax inequalities are earned. The lion's share of the sensitivity of preferred redistribution to source of inequality is attributable to male subjects (the average difference between "earned" and "unearned" methods being 14.5\%), with female subjects typically preferring more redistribution in all conditions and showing an average difference of only $4 \%$ between preferred redistribution in "earned" vs. "unearned" inequality conditions. We thus illuminate the sources of differences in voting by gender while also confirming a gender gap that is large and consistent with female voters' observed differential inclination to vote for candidates and parties associated with greater tax progressivity and more social spending.

How valid, if at all, is extrapolating from these findings to the political economy of taxation and redistribution? Clearly, our findings can be no more than suggestive, among other reasons because stakes averaging \$25 are small compared to U.S. annual incomes and because our experiment abstracts from production, investment, and the incentive issues attaching to them. But we can allay some other common concerns. For instance, experimentalists speak of an experimenter demand effect in which subjects do what they guess the experimenter wants them to do, and they worry about the possibility that subjects will take actions that appear economically irrational simply to avoid boredom if these are the only action opportunities offered them. Might our subjects have chosen to redistribute earnings simply to have something to do or because opportunities to dis-equalize were not on offer? Although our disinterested observer condition (Part I) could potentially suffer from such problems, several factors suggest to us that they are not major concerns.

First, Forsythe, Horowitz, Savin and Sefton (1994) find that first-mover sending is greatly reduced in dictator games when double-blindness is assured, as is the case in our design. Second, in our interested observer conditions, and especially after the resolution of uncertainty (Part III), most subjects had opportunities to choose distributions that were more unequal than the one maximizing their own earnings, and more did so when pre-tax incomes were earned, suggesting fairness concerns other than preferences for equality. That tax choices tended to vary systematically with self-interest, that they were responsive to direct and efficiency costs, and that they varied significantly with pre-tax income determination method, gender, and self-reported political philosophy, all suggest that perceived experimenter demand, or doing something rather than nothing, were not the main factors behind subjects decisions in our experiment.

In sum, our data appear to provide real insights into the demands for redistribution that play an important role in modern economies and polities. Use of experimental methods like ours with more diverse subject pools, including subjects in countries exhibiting different tax and transfer preferences than the United States, could further expand our understanding of why states redistribute.

\footnotetext{
${ }^{39}$ An average tax rate of $47 \%$ and $37 \%$ respectively.
} 


\section{REFERENCES}

Ackert, L. F., Martinez-Vazquez, J., Rider, M., Social Preferences and Tax Policy Design: Some Experimental Evidence, Economic Inquiry, 2007, 45, 3, 487-501.

Alesina, A., Angeletos, G.-M., Fairness and Redistribution: US versus Europe, American Economic Review, 2005, 95, 960-980.

Alesina, A., Di Tella, R., MacCulloch R., Inequality and Happiness: Are Americans and Europeans Different?, 2004, National Bureau of Economic Research Working Paper No. 8198.

Alesina, A., E. La Ferrara, Preferences for Redistribution in the Land of Opportunities, Journal of Public Economics, 2005, 89, 897-931.

Alesina, A., Rodrik, D., Distributive Politics and Economic Growth, Quarterly Journal of Economics, 1994, 109, 2, 465-490.

Amiel, Y., Cowell, F. A., Attitudes towards Risk and Inequality: A questionnaire-experimental Approach, in F. Andersson, H. J. Holm, Experimental Economics: Financial Markets, Auctions, and Decision Making, Chapter 9, pp. 85-115. Deventer: Kluwer, 2002.

Amiel, Y., Creedy, J., Hurn, S., Measuring Attitudes towards Inequality, Scandinavian Journal of Economics, 1999, 101, 1, 83.

Andreoni, J., Miller, J. H., Analyzing Choice with Revealed Preference: is Altruism Rational? , Working Papers 14, Wisconsin Madison Social Systems, 1998.

Andreoni J., Vesterlund, L., Which Is the Fair Sex? Gender Differences in Altruism, Quarterly Journal of Economics, 2001, 116, 293-312.

Beck, J. H., An Experimental Test of Preferences for the Distribution of Income and Individual Risk Aversion, Eastern Economic Journal, 1994, 20, 2, 131-145.

Beckman, S., Formby J. P., Smith, W. J., Efficiency, Equity and Democracy: Experimental Evidence on Okun's Leaky Bucket, in Cowell, F., Inequality, Welfare and Income Distribution: Experimental Approaches, JAI Press, 2004.

Bénabou, R., Unequal Societies: Income Distribution and the Social Contract, American Economic Review, 2000, 90, 1, 96-129.

Bénabou, R., E. Ok, Social Mobility and the Demand for Redistribution: the POUM Hypothesis, Quarterly Journal of Economics, 2001, 116 (2), 447-487.

Bénabou, R., Tirole, J., Belief in a Just World and Redistributive Politics, Quarterly Journal of Economics 2006, 121, 2, 699-746.

Bolton G. E., Ockenfels, A., ERC: A Theory of Equity, Reciprocity, and Competition, American Economic Review, 2000, 90, 1, 166-193.

Bosmans, K., Schokkaert, E., Social Welfare, the Veil of Ignorance and Purely Individual Risk: an Empirical Examination, in Cowell, F., Inequality, Welfare and Income Distribution: Experimental Approaches, JAI Press, 2004.

Burrows, P., Loomes, G., The impact of fairness on bargaining behavior, Empirical Economics, 1994, 19, 201-221.

Camerer, C., Behavioral Game Theory: Experiments in Strategic Interaction, Princeton University Press, Princeton, N.J, 2003. 
Charness G., Rabin, M., Understanding Social Preferences with Simple Tests, Quarterly Journal of Economics, 2002, 117, 3, 817-869.

Corneo, G., Gruner, H. P., Individual Preferences for Political Redistribution, Journal of Public Economics, 2002, 83, 83-107.

Corneo, G., Fong, C. M., What'Is the Monetary Value of Distributive Justice?, CEPR Discussion Paper No. 5227, 2005.

Cowell, F. A., Schokkaert, E., Risk Perceptions and Distributional Judgements, European Economic Review, 2001, 45, 941-52.

Davidovitz, L., Kroll, Y., On the Attitude toward Inequality, in Cowell, F., Inequality, Welfare and Income Distribution: Experimental Approaches, JAI Press, 2004.

Eckel, C. C., Grossman, P. J., Are Women Less Selfish than Men? Evidence from Dictator Experiments, Economic Jounal, 1998, 108, 726-35.

Engelmann D., Strobel, M., Inequality Aversion, Efficiency, and Maximin Preferences in Simple Distribution Experiments, American Economic Review, 2004, 94, 4, 857-869.

Fehr E., Schmidt, K. M., A Theory of Fairness, Competition, and Cooperation, Quarterly Journal of Economics, 1999, vol. 114(3), p. 817-868, August.

Fehr E., Schmidt, K. M., The Economics of Fairness, Reciprocity and Altruism - Experimental Evidence and New Theories, in Kolm, S.C., Ythier, J. M., Handbook of the Economics of Giving, Altruism and Reciprocity: Foundations, 2006, North-Holland.

Fehr E., Schmidt K. M., Theories of Fairness and Reciprocity - Evidence and Economic Applications, in Dewatripont, M. et al., Advances in Economics and Econometrics, Eighth World Congress of the Econometric Society, Vol. 1, Cambridge: Cambridge University Press (2003), 208-257.

Fong, C., Social Preferences, Self-interest, and the Demand for Redistribution, Journal of Public Economics, 2001, 82, 225-246.

Fong, C., Subjective Mobility, Redistributive Demands, and the Behavioral Assumptions of Economics, Typescript, 2003.

Forsythe, R., Horowitz, J., Savin N., Sefton, M. Fairness in Simple Bargaining Experiments, Games and Economic Behavior, 1994, 6, 347-369.

Frohlich, N., Oppenheimer, J., Choosing Justice: An Experimental Approach to Ethical Theory, Berkeley, 1992, University of California Press.

Gilens, M., Why Americans Hate Welfare: Race, Media, and the Politics of Anti-Poverty Policy, 1999, Chicago University Press.

Graham, C., Pettinato, S., Happiness and Hardship, Brookings Institution Press, Washington, D.C., 2002.

Guth, W., Kliemt, H., Ockenfels, A., Fariness versus Efficiency: an Experimental Study of (Mutual) Gift Giving, Journal of Economic Behaviour and Organizations, 2002, 50, 465-75.

Harsanyi, J. C., Cardinal Utility in Welfare Economics and in the Theory of Risk-taking, Journal of Political Economy, 1953, 61, 434-435.

Harsanyi, J. C., Cardinal Welfare, Individualistic Ethics and Interpersonal Comparisons of Utility, Journal of Political Economy, 1955, 63, 309-321. 
Harsanyi, J. C., Rational Behavior and Bargaining Equilibrium in Games and Social Situations, Cambridge, Cambridge University Press, 1977.

Harsanyi, J. C., Bayesian Decision Theory and Utilitarian Ethics, American Economic Review, 1978, 68, 223-228.

Herne, K. and Suojanen, M., The Role of Information in Choices over Income Distributions, Journal of Conflict Resolution, 2004, 48, 173-193.

Hoffman, E., Spitzer, L., Entitlements, Rights, and Fairness: An Experimental Examination of Subjects' Concepts of Distributive Justice, The Journal of Legal Studies, 1985, 14, 2, 259-297.

Johansson-Stenman, O., Carlsson, F., Daruvala, D., Measuring Future Grandparents' Preferences for Equality and Relative Standing, Economic Journal, 2002, 112, 362-383.

Kaufmann, K. M., Petrocik, J.R., The Changing Politics of American Men: Understanding the Sources of the Gender Gap, American Journal of Political Science, 199, 43, 3, 864-887.

Krawczyk, M., A glimpse through the veil of ignorance: equality of opportunity and support for redistribution, 2007 Working Paper.

Meltzer, A., Richard, S., A Rational Theory of the Size of Government, Journal of Political Economy, 1981, 89 (5), 814-927.

Milanovic, B., The Median-voter Hypothesis, Income Inequality, and Income Redistribution, an Empirical Test with the Required Data, European Journal of Political Economy, 2000, 6 (3): 367-410.

Mittone, L., Fairness-Based Altruism and Redistribution: an Experimental Approach, in Cowell, F., Inequality, Welfare and Income Distribution: Experimental Approaches, JAI Press, 2004.

Norrander, B., Wilcox, C., The Gender Gap in Ideology, Political Behavior, 2008, 30, 4, 503-523.

Okun, A, Equality and Efficiency: The Big Trade-off, The Brookings Institution, Washington, 1975.

Piketty, T., Social Mobility and Redistributive Politics, Quarterly Journal of Economics, 1995, 110, 551584.

Piketty, T., Attitudes Toward Income Inequality in France: Do People Really Disagree?, 1999, CEPREMAP Working Papers 9918, CEPREMAP.

Rabin, M., Incorporating Fairness into Game Theory, American Economic Review, 1993, 83 (5), 1281 1302 .

Ravallion, M., Lokshin, M., Who Wants to Redistribute? The Tunnel Effect in 1990s Russia, Journal of Public Economics, 2000, 76, 87-104.

Rutstrom, E., Williams, M. B., Entitlements and Fairness: An Experimental Study of Distributive Preferences, Journal of Economic Behavior and Organization, 2000, 43, 75-89.

Sinn, H.W., A Theory of the Welfare State, Scandinavian Journal of Economics, 1995, 97: 495-526.

Thurow, L., The Income Distribution as a Pure Public Good, Quarterly Journal of Economics, 1971, 85, 2, 327-336.

Vickrey, W., Measuring Marginal Utility by Reaction to Risk, Econometrica, 1945, 13, 319-333. 
Table 1. Part I Participants' Earnings Distribution under Different Tax Rates (with efficiency loss=0\%)

\begin{tabular}{|c|c|c|c|c|c|c|c|c|c|c|c|}
\hline Rank & $t=0 \%$ & $t=10 \%$ & $t=20 \%$ & $t=30 \%$ & $t=40 \%$ & $t=50 \%$ & $t=60 \%$ & $t=70 \%$ & $t=80 \%$ & $t=90 \%$ & $t=100 \%$ \\
\hline 1 & 100.0 & 92.0 & 84.0 & 75.9 & 67.9 & 59.9 & 51.9 & 43.9 & 35.8 & 27.8 & 19.8 \\
\hline 2 & 46.1 & 43.4 & 40.8 & 38.2 & 35.6 & 32.9 & 30.3 & 27.7 & 25.1 & 22.4 & 19.8 \\
\hline 3 & 36.6 & 34.9 & 33.2 & 31.5 & 29.9 & 28.2 & 26.5 & 24.8 & 23.2 & 21.5 & 19.8 \\
\hline 4 & 30.8 & 29.7 & 28.6 & 27.5 & 26.4 & 25.3 & 24.2 & 23.1 & 22.0 & 20.9 & 19.8 \\
\hline 5 & 26.5 & 25.9 & 25.2 & 24.5 & 23.8 & 23.2 & 22.5 & 21.8 & 21.2 & 20.5 & 19.8 \\
\hline 6 & 23.3 & 23.0 & 22.6 & 22.3 & 21.9 & 21.6 & 21.2 & 20.9 & 20.5 & 20.2 & 19.8 \\
\hline 7 & 20.6 & 20.5 & 20.5 & 20.4 & 20.3 & 20.2 & 20.1 & 20.1 & 20.0 & 19.9 & 19.8 \\
\hline 8 & 18.4 & 18.6 & 18.7 & 18.8 & 19.0 & 19.1 & 19.3 & 19.4 & 19.5 & 19.7 & 19.8 \\
\hline 9 & 16.3 & 16.6 & 17.0 & 17.3 & 17.7 & 18.0 & 18.4 & 18.8 & 19.1 & 19.5 & 19.8 \\
\hline 10 & 14.5 & 15.0 & 15.5 & 16.1 & 16.6 & 17.1 & 17.7 & 18.2 & 18.7 & 19.3 & 19.8 \\
\hline 11 & 12.7 & 13.4 & 14.1 & 14.9 & 15.6 & 16.3 & 17.0 & 17.7 & 18.4 & 19.1 & 19.8 \\
\hline 12 & 11.1 & 12.0 & 12.9 & 13.7 & 14.6 & 15.5 & 16.3 & 17.2 & 18.1 & 18.9 & 19.8 \\
\hline 13 & 9.6 & 10.6 & 11.6 & 12.6 & 13.7 & 14.7 & 15.7 & 16.7 & 17.8 & 18.8 & 19.8 \\
\hline 14 & 8.1 & 9.3 & 10.5 & 11.6 & 12.8 & 14.0 & 15.1 & 16.3 & 17.5 & 18.6 & 19.8 \\
\hline 15 & 6.8 & 8.1 & 9.4 & $\begin{array}{l}10.7 \\
\end{array}$ & 12.0 & 13.3 & 14.6 & 15.9 & 17.2 & 18.5 & $\begin{array}{l}19.8 \\
\end{array}$ \\
\hline 16 & 5.5 & 7.0 & 8.4 & 9.8 & 11.2 & 12.7 & 14.1 & 15.5 & 17.0 & 18.4 & 19.8 \\
\hline 17 & 4.3 & 5.9 & $\begin{array}{l}7.4 \\
\end{array}$ & 9.0 & 10.5 & 12.1 & 13.6 & 15.2 & 16.7 & 18.3 & $\begin{array}{l}19.8 \\
\end{array}$ \\
\hline 18 & 3.1 & 4.8 & 6.4 & 8.1 & 9.8 & 11.5 & 13.1 & 14.8 & 16.5 & 18.1 & 19.8 \\
\hline 19 & 1.5 & 3.3 & 5.2 & 7.0 & 8.8 & 10.7 & 12.5 & 14.3 & 16.1 & 18.0 & 19.8 \\
\hline 20 & 0.1 & 2.1 & 4.0 & 6.0 & 8.0 & 10.0 & 11.9 & 13.9 & 15.9 & \begin{tabular}{|l|l}
17.8 \\
\end{tabular} & $\begin{array}{l}19.8 \\
\end{array}$ \\
\hline
\end{tabular}




\section{Figure 1. Sequence of the Experimental Session}

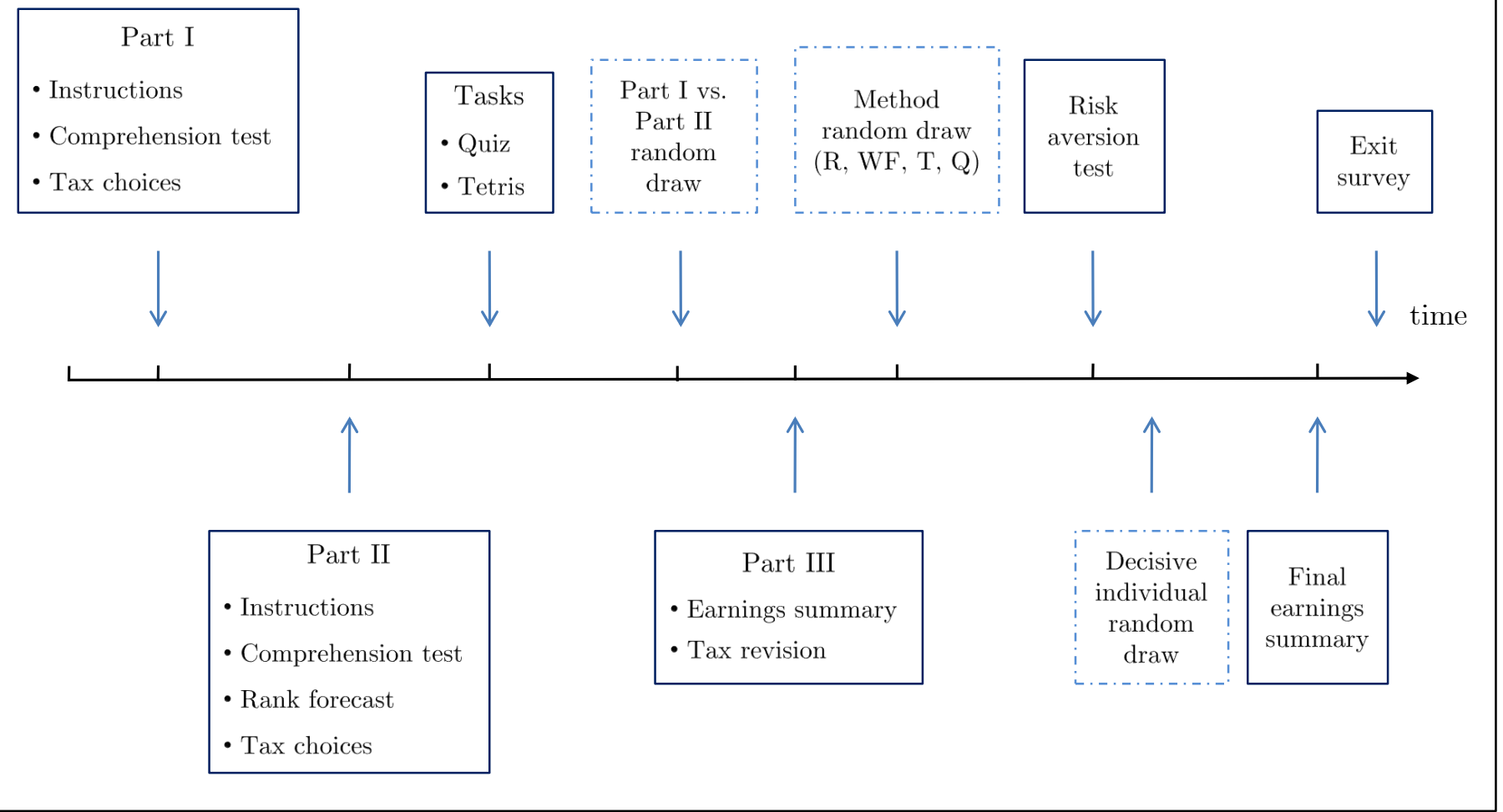


Table 2. Experimental Sessions and Subjects by Tax Cost and Dead Weight Loss

\begin{tabular}{|c|c|cccc|c|}
\hline \multicolumn{2}{|c|}{} & \multicolumn{5}{|c|}{ Tax Cost } \\
\cline { 2 - 7 } & $\$ 0$ & $\$ 0.25$ & $\$ 0.50$ & $\$ 1$ & Total \\
\hline \multirow{3}{*}{ Dead Weight Loss } & $0 \%$ & $2(42)$ & $2(42)$ & $2(42)$ & $2(42)$ & $8(168)$ \\
& $12.5 \%$ & $1(21)$ & $1(21)$ & $1(20)$ & $1(21)$ & $4(83)$ \\
& $25 \%$ & $1(21)$ & $1(21)$ & $1(21)$ & $1(21)$ & $4(84)$ \\
\cline { 2 - 7 } & Total & $4(84)$ & $4(84)$ & $4(83)$ & $4(84)$ & $\mathbf{1 6}(\mathbf{3 3 6})$ \\
\hline
\end{tabular}

Note: numbers in parenthesis indicate the total number of subjects participating in the experimental sessions.

Figure 2. Part 1 Average Tax Rate by Tax Cost and Efficiency Loss
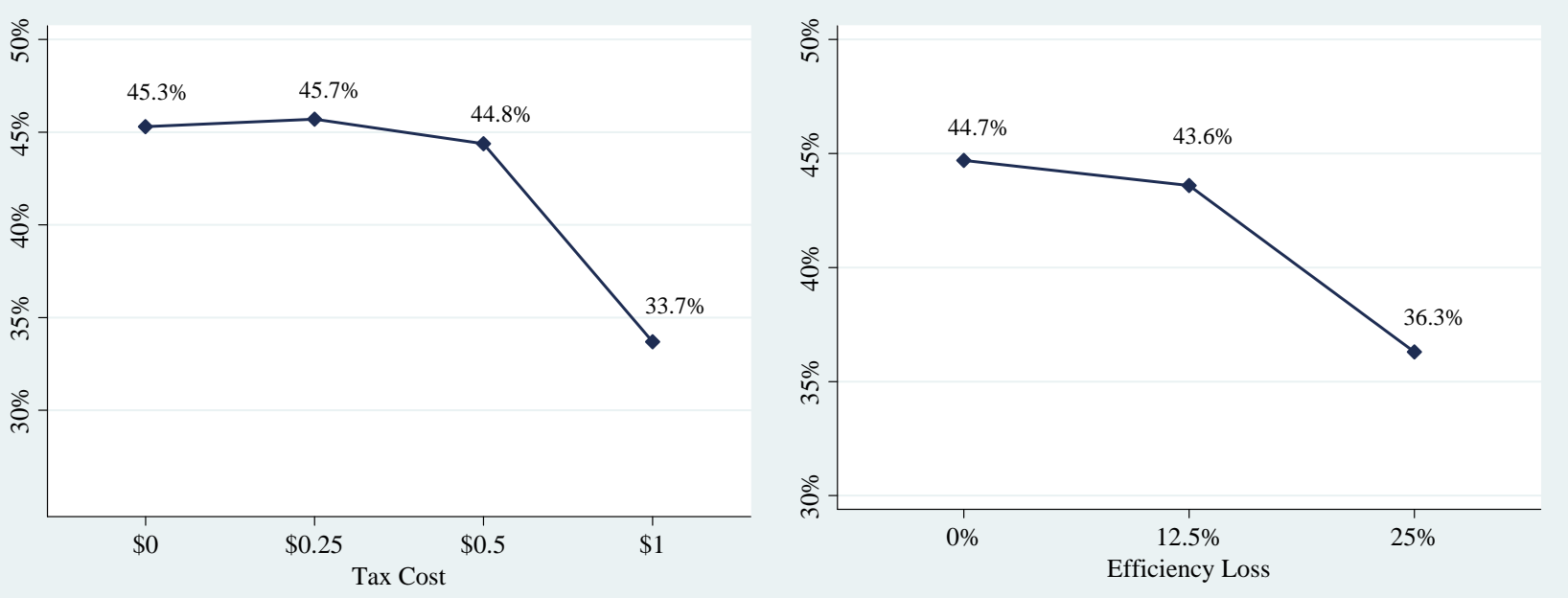
Table 3. Tobit Regressions for Part I (All methods)

Dependent variable: Part I Tax Choice

$\begin{array}{lllllll}(1) & (2) & (3) & \text { (4) } & \text { (5) } & \text { (6) } & \text { (7) }\end{array}$

\begin{tabular}{|c|c|c|c|c|c|c|c|}
\hline Tax Cost & $\begin{array}{c}-0.116^{* * *} \\
(0.021)\end{array}$ & $\begin{array}{c}-0.117 * * * \\
(0.021)\end{array}$ & $\begin{array}{c}-0.113^{* * *} \\
(0.022)\end{array}$ & $\begin{array}{c}-0.113^{* * *} \\
(0.021)\end{array}$ & $\begin{array}{c}-0.116^{* * *} \\
(0.021)\end{array}$ & $\begin{array}{c}-0.105^{* * *} \\
(0.022)\end{array}$ & $\begin{array}{c}-0.105^{* * *} \\
(0.022)\end{array}$ \\
\hline Efficiency Loss & $\begin{array}{c}-0.082 * * * \\
(0.022)\end{array}$ & $\begin{array}{c}-0.082 * * * \\
(0.022)\end{array}$ & $\begin{array}{c}-0.071 * * * \\
(0.022)\end{array}$ & $\begin{array}{c}-0.087 * * * \\
(0.022)\end{array}$ & $\begin{array}{c}-0.077 * * * \\
(0.022)\end{array}$ & $\begin{array}{c}-0.073^{* * *} \\
(0.022)\end{array}$ & $\begin{array}{c}-0.073 * * * \\
(0.022)\end{array}$ \\
\hline WF & & $\begin{array}{l}-0.040 \\
(0.027)\end{array}$ & $\begin{array}{c}-0.041 \\
(0.027)\end{array}$ & $\begin{array}{l}-0.041 \\
(0.027)\end{array}$ & $\begin{array}{l}-0.040 \\
(0.027)\end{array}$ & $\begin{array}{l}-0.042 \\
(0.027)\end{array}$ & \\
\hline Tetris & & $\begin{array}{c}-0.113^{* * *} \\
(0.026)\end{array}$ & $\begin{array}{c}-0.115^{* * *} \\
(0.026)\end{array}$ & $\begin{array}{c}-0.114^{* * * *} \\
(0.026)\end{array}$ & $\begin{array}{c}-0.114^{* * *} \\
(0.026)\end{array}$ & $\begin{array}{c}-0.116^{* * *} \\
(0.026)\end{array}$ & \\
\hline Quiz & & $\begin{array}{c}-0.111^{* * *} \\
(0.026)\end{array}$ & $\begin{array}{c}-0.113^{* * *} \\
(0.026)\end{array}$ & $\begin{array}{c}-0.112^{* * *} \\
(0.026)\end{array}$ & $\begin{array}{c}-0.113^{* * *} \\
(0.026)\end{array}$ & $\begin{array}{c}-0.114^{* * *} \\
(0.026)\end{array}$ & \\
\hline Tetris-Quiz & & & & & & & $\begin{array}{c}-0.096 * * * \\
(0.019)\end{array}$ \\
\hline Female & & & $\begin{array}{c}0.133^{* * *} \\
(0.019)\end{array}$ & & & $\begin{array}{c}0.105^{* * *} \\
(0.020)\end{array}$ & $\begin{array}{c}0.104^{* * *} \\
(0.020)\end{array}$ \\
\hline Asian & & & $\begin{array}{c}0.002 \\
(0.026)\end{array}$ & & & $\begin{array}{c}0.006 \\
(0.026)\end{array}$ & $\begin{array}{c}0.006 \\
(0.026)\end{array}$ \\
\hline African American & & & $\begin{array}{l}-0.007 \\
(0.038)\end{array}$ & & & $\begin{array}{l}-0.052 \\
(0.038)\end{array}$ & $\begin{array}{l}-0.052 \\
(0.038)\end{array}$ \\
\hline Hispanic & & & $\begin{array}{c}0.026 \\
(0.040)\end{array}$ & & & $\begin{array}{l}-0.001 \\
(0.040)\end{array}$ & $\begin{array}{l}-0.001 \\
(0.040)\end{array}$ \\
\hline Income & & & & $\begin{array}{l}-0.031^{*} \\
(0.016)\end{array}$ & & $\begin{array}{c}-0.037^{* *} \\
(0.016)\end{array}$ & $\begin{array}{c}-0.037^{* *} \\
(0.016)\end{array}$ \\
\hline Risk Aversion & & & & $\begin{array}{c}0.010^{* * *} \\
(0.002)\end{array}$ & & $\begin{array}{c}0.007 * * * \\
(0.002)\end{array}$ & $\begin{array}{c}0.007^{* * *} \\
(0.002)\end{array}$ \\
\hline Political Philosophy & & & & & $\begin{array}{c}0.034 * * * \\
(0.008)\end{array}$ & $\begin{array}{c}0.033^{* * *} \\
(0.008)\end{array}$ & $\begin{array}{c}0.033^{* * *} \\
(0.008)\end{array}$ \\
\hline Economics Courses & & & & & $\begin{array}{c}-0.014^{* * *} \\
(0.005)\end{array}$ & $\begin{array}{c}-0.012^{* * *} \\
(0.005)\end{array}$ & $\begin{array}{c}-0.012 * * * \\
(0.005)\end{array}$ \\
\hline Constant & $\begin{array}{c}0.303 * * * \\
(0.012)\end{array}$ & $\begin{array}{c}0.374 * * * \\
(0.021)\end{array}$ & $\begin{array}{c}0.312 * * * \\
(0.024)\end{array}$ & $\begin{array}{c}0.645^{* * *} \\
(0.164)\end{array}$ & $\begin{array}{c}0.220 * * * \\
(0.047)\end{array}$ & $\begin{array}{c}0.519^{* * *} \\
(0.178)\end{array}$ & $\begin{array}{c}0.496 * * * \\
(0.177)\end{array}$ \\
\hline Observations & 1340 & 1340 & 1340 & 1340 & 1340 & 1340 & 1340 \\
\hline Uncensored observations & 837 & 837 & 837 & 837 & 837 & 837 & 837 \\
\hline Left-censored observations & 316 & 316 & 316 & 316 & 316 & 316 & 316 \\
\hline Right-censored observations & 187 & 187 & 187 & 187 & 187 & 187 & 187 \\
\hline Log Likelihood & -1155 & -1142 & -1118 & -1131 & -1125 & -1098 & -1099 \\
\hline Chi2 & 40.334 & 66.378 & 113.711 & 88.816 & 100.115 & 154.259 & 151.816 \\
\hline Pseudo-R square & 0.017 & 0.028 & 0.048 & 0.038 & 0.043 & 0.066 & 0.065 \\
\hline
\end{tabular}

Coefficients are marginal effects. Standard errors in parentheses; * significant at 10\%; ** significant at 5\%; *** significant at $1 \%$. 
Figure 3. Part I Average Tax Choice by Method

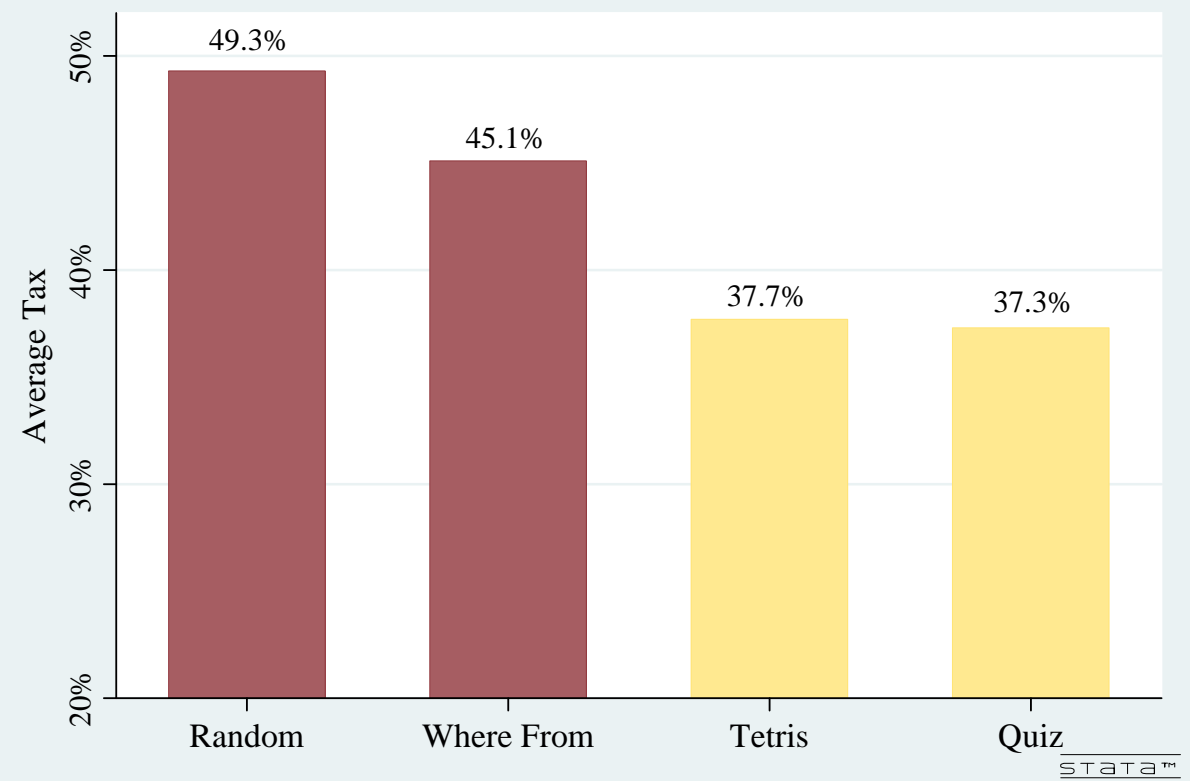

Figure 4. Part I Average Tax Choice by Method and Gender

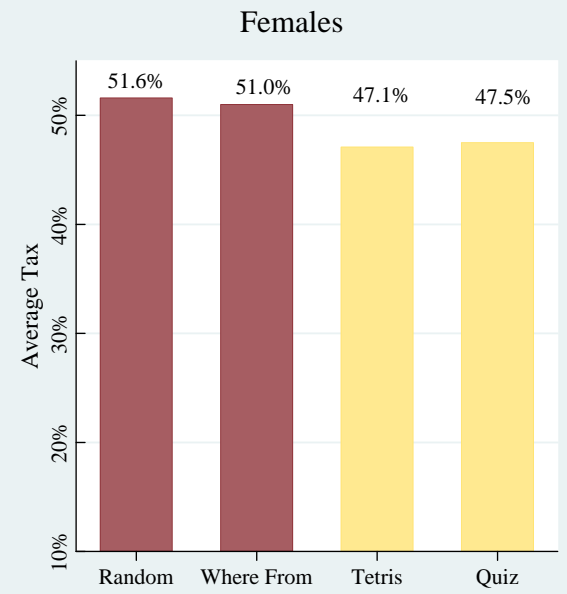

Males

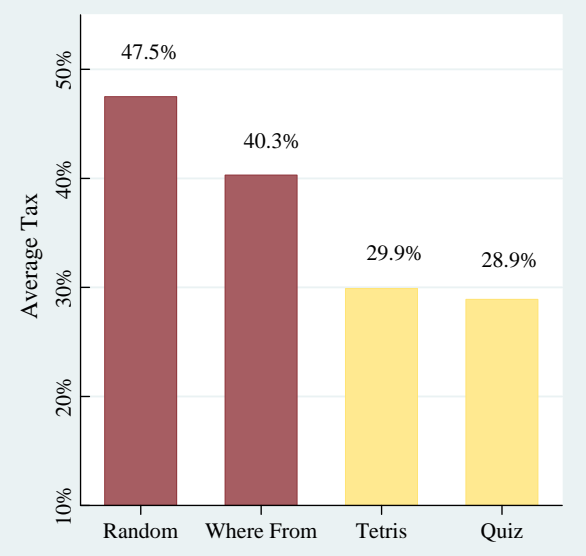


Table 4. Tobit Regressions for Part I with Gender Interaction Terms

Dependent variable: Part I Tax Choice
(1)
(2)
(3)
(4)
(5)

\begin{tabular}{|c|c|c|c|c|c|}
\hline Tax Cost & $\begin{array}{c}-0.105^{* * *} \\
(0.022)\end{array}$ & $\begin{array}{c}-0.105^{* * *} \\
(0.022)\end{array}$ & $\begin{array}{c}-0.141^{* * *} \\
(0.028)\end{array}$ & $\begin{array}{c}-0.105^{* * *} \\
(0.022)\end{array}$ & $\begin{array}{c}-0.142 * * * \\
(0.028)\end{array}$ \\
\hline Efficiency Loss & $\begin{array}{c}-0.073 * * * \\
(0.022)\end{array}$ & $\begin{array}{c}-0.073 * * * \\
(0.022)\end{array}$ & $\begin{array}{c}-0.073^{* * *} \\
(0.022)\end{array}$ & $\begin{array}{c}-0.113^{* * *} \\
(0.028)\end{array}$ & $\begin{array}{c}-0.114^{* * * *} \\
(0.028)\end{array}$ \\
\hline Female & $\begin{array}{c}0.104 * * * \\
(0.020)\end{array}$ & $\begin{array}{l}0.055^{*} \\
(0.028)\end{array}$ & $\begin{array}{c}0.083 * * * \\
(0.023)\end{array}$ & $\begin{array}{c}0.081^{* * *} \\
(0.023)\end{array}$ & $\begin{array}{c}0.009 \\
(0.032)\end{array}$ \\
\hline Tetris-Quiz & $\begin{array}{c}-0.096 * * * \\
(0.019)\end{array}$ & $\begin{array}{c}-0.142 * * * \\
(0.026)\end{array}$ & $\begin{array}{c}-0.096 * * * \\
(0.019)\end{array}$ & $\begin{array}{c}-0.096 * * * \\
(0.019)\end{array}$ & $\begin{array}{c}-0.143^{* * *} \\
(0.026)\end{array}$ \\
\hline Female* Tetris-Quiz & & $\begin{array}{c}0.100 * * * \\
(0.039)\end{array}$ & & & $\begin{array}{c}0.101^{* * *} \\
(0.039)\end{array}$ \\
\hline Female $*$ Tax Cost & & & $\begin{array}{l}0.086^{*} \\
(0.046)\end{array}$ & & $\begin{array}{l}0.088^{*} \\
(0.046)\end{array}$ \\
\hline Female*Efficiency Loss & & & & $\begin{array}{c}0.099 * * \\
(0.046)\end{array}$ & $\begin{array}{l}0.100^{* *} \\
(0.046)\end{array}$ \\
\hline Constant & $\begin{array}{c}0.496 * * * \\
(0.177)\end{array}$ & $\begin{array}{l}0.52 * * * \\
(0.177)\end{array}$ & $\begin{array}{c}0.426^{* *} \\
(0.178)\end{array}$ & $\begin{array}{c}0.475^{* * *} \\
(0.178)\end{array}$ & $\begin{array}{c}0.529 * * * \\
(0.178)\end{array}$ \\
\hline Observations & 1340 & 1340 & 1340 & 1340 & 1340 \\
\hline Uncensored observations & 837 & 837 & 837 & 837 & 837 \\
\hline Left-censored observations & 316 & 316 & 316 & 316 & 316 \\
\hline Right-censored observations & 187 & 187 & 187 & 187 & 187 \\
\hline Log Likelihood & -1099 & -1096 & -1097 & -1097 & -1092 \\
\hline Chi2 & 151.816 & 158.535 & 155.380 & 156.396 & 166.914 \\
\hline Pseudo-R square & 0.065 & 0.067 & 0.066 & 0.067 & 0.071 \\
\hline
\end{tabular}

The following controls are included in the regression and maintain the expected sign and statistical significance: measure of risk aversion, ethnic dummies, log income, self-reported political identification, \# of economics courses taken.

Coefficients shown are marginal effects. Standard errors in parentheses; * significant at 10\%; ** significant at 5\%; *** significant at $1 \%$. 
Table 5. Tobit Regressions for Parts I and II Pooled (Random Method)

Dependent variable: Part I and II Tax Choice

(1)

\begin{tabular}{|c|c|c|c|}
\hline Tax Cost & $\begin{array}{c}-0.145^{* * *} \\
(0.032)\end{array}$ & $\begin{array}{c}-0.145^{* * *} \\
(0.031)\end{array}$ & $\begin{array}{c}-0.145 * * * \\
(0.031)\end{array}$ \\
\hline Efficiency Loss & $\begin{array}{c}-0.101^{* * *} \\
(0.032)\end{array}$ & $\begin{array}{c}-0.101^{* * *} \\
(0.032)\end{array}$ & $\begin{array}{c}-0.101^{* * * *} \\
(0.032)\end{array}$ \\
\hline Female & $\begin{array}{c}0.017 \\
(0.029)\end{array}$ & $\begin{array}{c}0.017 \\
(0.029)\end{array}$ & $\begin{array}{c}0.017 \\
(0.029)\end{array}$ \\
\hline Income & $\begin{array}{c}0.047 * * \\
(0.024)\end{array}$ & $\begin{array}{c}0.047 * * \\
(0.023)\end{array}$ & $\begin{array}{c}0.047 * * \\
(0.023)\end{array}$ \\
\hline Risk Aversion & $\begin{array}{l}0.008 * * \\
(0.003)\end{array}$ & $\begin{array}{l}0.008 * * \\
(0.003)\end{array}$ & $\begin{array}{l}0.010 * * \\
(0.005)\end{array}$ \\
\hline Political Philosophy & $\begin{array}{c}0.045^{* * *} \\
(0.011)\end{array}$ & $\begin{array}{c}0.045^{* * * *} \\
(0.011)\end{array}$ & $\begin{array}{c}0.045^{* * *} \\
(0.011)\end{array}$ \\
\hline Economics Courses & $\begin{array}{c}-0.021^{* * *} \\
(0.007)\end{array}$ & $\begin{array}{c}-0.021^{* * *} \\
(0.007)\end{array}$ & $\begin{array}{c}-0.021^{* * *} \\
(0.007)\end{array}$ \\
\hline Part II & & $\begin{array}{c}0.059 * * \\
(0.027)\end{array}$ & $\begin{array}{l}0.076^{*} \\
(0.043)\end{array}$ \\
\hline Part II * Risk Aversion & & & $\begin{array}{l}-0.003 \\
(0.007)\end{array}$ \\
\hline Constant & $\begin{array}{c}-0.311 \\
{[0.253]}\end{array}$ & $\begin{array}{c}-0.342 \\
{[0.253]}\end{array}$ & $\begin{array}{c}-0.351 \\
{[0.254]}\end{array}$ \\
\hline Observations & 670 & 670 & 670 \\
\hline Uncensored observations & 421 & 421 & 421 \\
\hline Left-censored observations & 111 & 111 & 111 \\
\hline Right-censored observations & 138 & 138 & 138 \\
\hline Log Likelihood & -552 & -550 & -550 \\
\hline Pseudo-R square & 0.068 & 0.072 & 0.072 \\
\hline Chi2 & 80.924 & 85.557 & 85.815 \\
\hline
\end{tabular}

Ethnic dummies are included in the regression. Coefficients shown are marginal effects.

Standard errors in parentheses; * significant at 10\%; ** significant at 5\%; *** significant at $1 \%$ 
Table 6. Tobit Regressions for Part II with Expected Rank and Confidence (WF, Tetris, and Quiz Methods) Dependent variable: Part II Tax Choice

\begin{tabular}{|c|c|c|c|c|c|}
\hline \multicolumn{6}{|c|}{ Dependent variable: Part II Tax Choice } \\
\hline & (1) & (2) & (3) & (4) & (5) \\
\hline Tax Cost & $\begin{array}{c}-0.088 * * * \\
(0.024)\end{array}$ & $\begin{array}{c}-0.094 * * * \\
(0.023)\end{array}$ & $\begin{array}{c}-0.093^{* * *} \\
(0.023)\end{array}$ & $\begin{array}{c}-0.093 * * * \\
(0.023)\end{array}$ & $\begin{array}{c}-0.093^{* * *} \\
(0.023)\end{array}$ \\
\hline Efficiency Loss & $\begin{array}{c}-0.073^{* * *} \\
(0.025)\end{array}$ & $\begin{array}{c}-0.076^{* * *} \\
(0.024)\end{array}$ & $\begin{array}{c}-0.070^{* * *} \\
(0.024)\end{array}$ & $\begin{array}{c}-0.070 * * * \\
(0.024)\end{array}$ & $\begin{array}{c}-0.065^{* * *} \\
(0.024)\end{array}$ \\
\hline Female & $\begin{array}{c}0.133^{* * *} \\
(0.022)\end{array}$ & $\begin{array}{c}0.084^{* * *} \\
(0.022)\end{array}$ & $\begin{array}{c}0.083^{* * *} \\
(0.022)\end{array}$ & $\begin{array}{c}0.096 * * * \\
(0.022)\end{array}$ & $\begin{array}{c}0.094 * * * \\
(0.022)\end{array}$ \\
\hline Home Area Income & $\begin{array}{c}-0.109 * * * \\
(0.019)\end{array}$ & $\begin{array}{c}-0.040^{* *} \\
(0.018)\end{array}$ & $\begin{array}{c}-0.038^{* *} \\
(0.018)\end{array}$ & $\begin{array}{l}-0.029 \\
(0.019)\end{array}$ & $\begin{array}{l}-0.028 \\
(0.019)\end{array}$ \\
\hline Risk Aversion & $\begin{array}{c}0.008 * * * \\
(0.003)\end{array}$ & $\begin{array}{c}0.005^{* *} \\
(0.003)\end{array}$ & $\begin{array}{c}0.005^{* *} \\
(0.003)\end{array}$ & $\begin{array}{c}0.006^{* *} \\
(0.003)\end{array}$ & $\begin{array}{c}0.005^{* *} \\
(0.003)\end{array}$ \\
\hline Political Philosophy & $\begin{array}{c}0.025^{* * *} \\
(0.009)\end{array}$ & $\begin{array}{l}0.021^{* *} \\
(0.008)\end{array}$ & $\begin{array}{l}0.020^{* *} \\
(0.008)\end{array}$ & $\begin{array}{c}0.022 * * * \\
(0.008)\end{array}$ & $\begin{array}{l}0.020^{* *} \\
(0.008)\end{array}$ \\
\hline Economics Courses & $\begin{array}{l}-0.007 \\
(0.005)\end{array}$ & $\begin{array}{l}-0.005 \\
(0.005)\end{array}$ & $\begin{array}{c}-0.004 \\
(0.005)\end{array}$ & $\begin{array}{c}-0.004 \\
(0.005)\end{array}$ & $\begin{array}{c}-0.003 \\
(0.005)\end{array}$ \\
\hline Tetris-Quiz & $\begin{array}{c}-0.065^{* * *} \\
(0.023)\end{array}$ & $\begin{array}{c}-0.044^{* *} \\
(0.022)\end{array}$ & $\begin{array}{c}-0.055^{* *} \\
(0.022)\end{array}$ & $\begin{array}{c}0.114^{* *} \\
(0.049)\end{array}$ & $\begin{array}{l}0.097^{*} \\
(0.050)\end{array}$ \\
\hline Expected Rank & & $\begin{array}{c}0.038^{* * *} \\
(0.003)\end{array}$ & $\begin{array}{c}0.034^{* * *} \\
(0.003)\end{array}$ & $\begin{array}{c}0.048 * * * \\
(0.004)\end{array}$ & $\begin{array}{c}0.044^{* * *} \\
(0.004)\end{array}$ \\
\hline Confidence & & & $\begin{array}{c}-0.182^{* * *} \\
(0.048)\end{array}$ & & $\begin{array}{c}-0.168 * * * \\
(0.048)\end{array}$ \\
\hline Confidence*Expected Rank & & & $\begin{array}{c}0.012 * * \\
(0.005)\end{array}$ & & $\begin{array}{l}0.010^{*} \\
(0.005)\end{array}$ \\
\hline Tetris-Quiz * Expected Rank & & & & $\begin{array}{c}-0.017^{* * *} \\
(0.005)\end{array}$ & $\begin{array}{c}-0.016^{* * *} \\
(0.005)\end{array}$ \\
\hline Observations & 1005 & 1005 & 1005 & 1005 & 1005 \\
\hline Uncensored observations & 651 & 651 & 651 & 651 & 651 \\
\hline Left-censored observations & 237 & 237 & 237 & 237 & 237 \\
\hline Right-censored observations & 117 & 117 & 117 & 117 & 117 \\
\hline Log Likelihood & -762 & -651 & -644 & -645 & -638 \\
\hline Pseudo-R square & 0.091 & 0.225 & 0.233 & 0.232 & 0.240 \\
\hline Chi2 & 153.538 & 377.084 & 391.272 & 388.963 & 402.048 \\
\hline
\end{tabular}

Ethnic dummies are included in the regression. Coefficients shown are marginal effects. Standard errors in parentheses; * significant at 10\%; ** significant at 5\%; *** significant at $1 \%$ 
Figure 5. Part II Tax Choices Distribution by Expected Rank

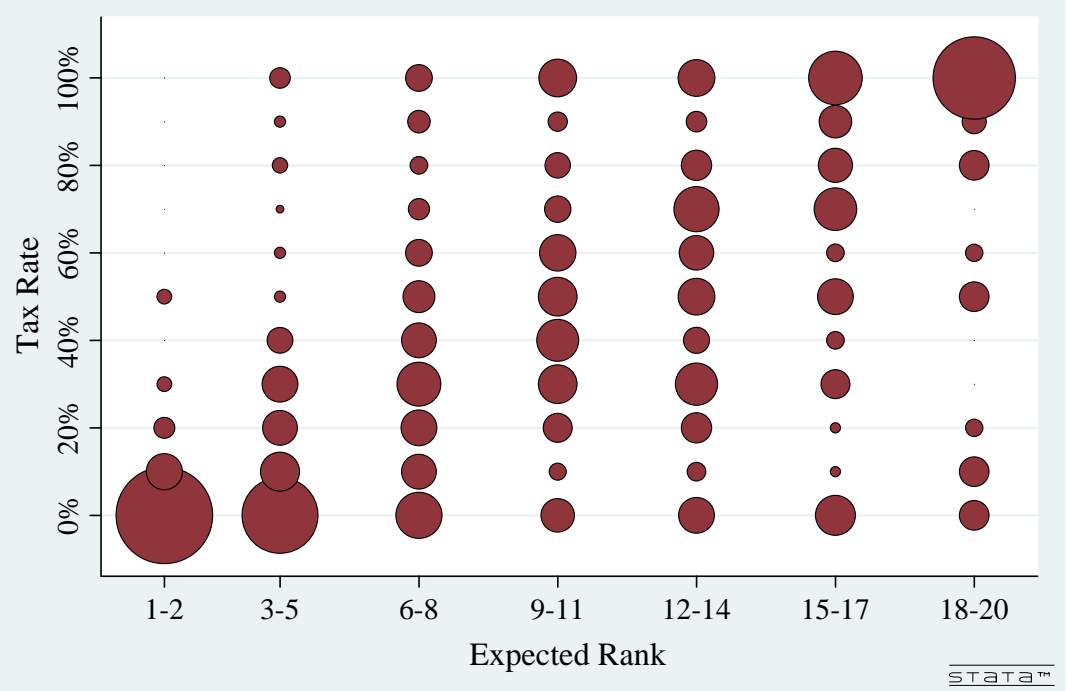

Figure 6. Part III. Average Tax Choice by Total Cost of Taxation

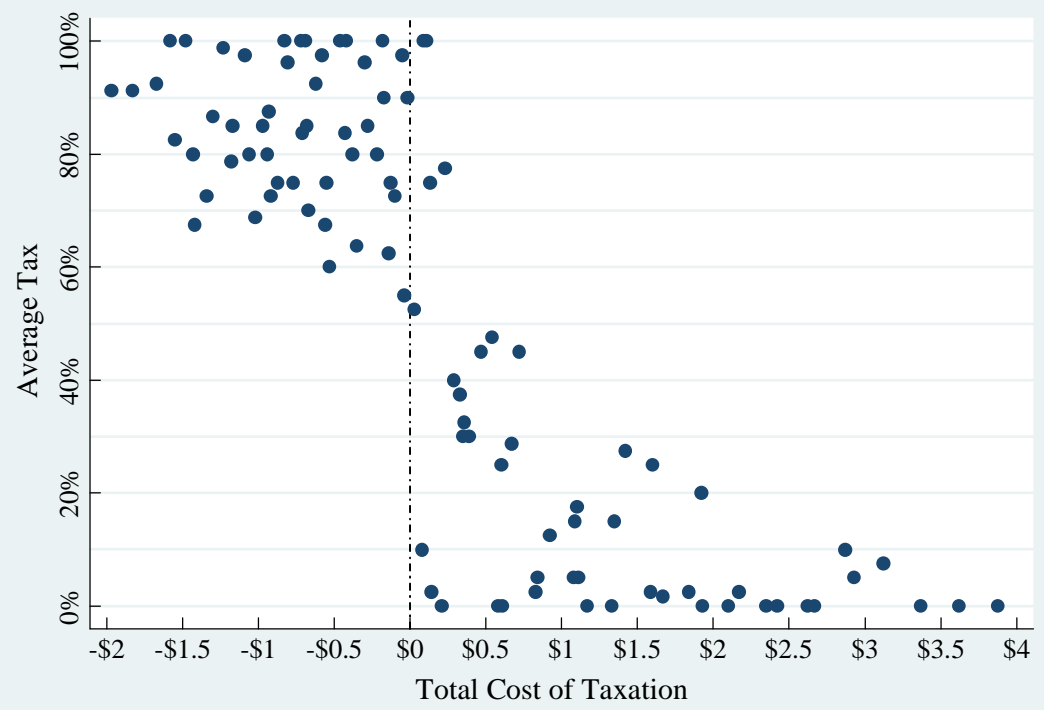

Note: the "Total Cost of Taxation" includes the regular tax cost parameter used in the experimental session as well as the additionall cost of redistribution which depends on each individual's revealed rank. 
Table 7. Tobit Regressions for Part III (All Methods)

Dependent variable: Part III Tax Choice

\begin{tabular}{ccc} 
& $(1)$ & $(2)$ \\
\hline Tot. Cost of Taxation (\$ per 10\%) & $-0.360^{* * *}$ & $-0.346^{* * *}$ \\
Total Cost of Taxation ${ }^{2}$ & $(0.053)$ & $(0.054)$ \\
& $0.032^{* * *}$ & $0.030^{* * *}$ \\
Earnings-Maximising Tax Rate & $(0.006)$ & $(0.006)$ \\
& $0.312^{* * *}$ & $0.345^{* * *}$ \\
EMTR * Cost of Taxation & $(0.065)$ & $(0.064)$ \\
& $0.358^{* * *}$ & $0.365^{* * *}$ \\
Part I Tax & $(0.080)$ & $(0.081)$ \\
& & $0.309^{* * *}$ \\
Observations & & $(0.059)$ \\
\hline Uncensored observations & 588 & 588 \\
Left-censored observations & 149 & 149 \\
Right-censored observations & 197 & 197 \\
Log Likelihood & 242 & -429 \\
Pseudo-R square & -443 & 0.324 \\
Chi2 & 0.302 & 411.091 \\
& 383.574 & \\
Coefficients shown are marginal effects. Standard errors in parentheses; * significant at 10\%; \\
significant at 5\%; *** significant at 1\%.
\end{tabular}



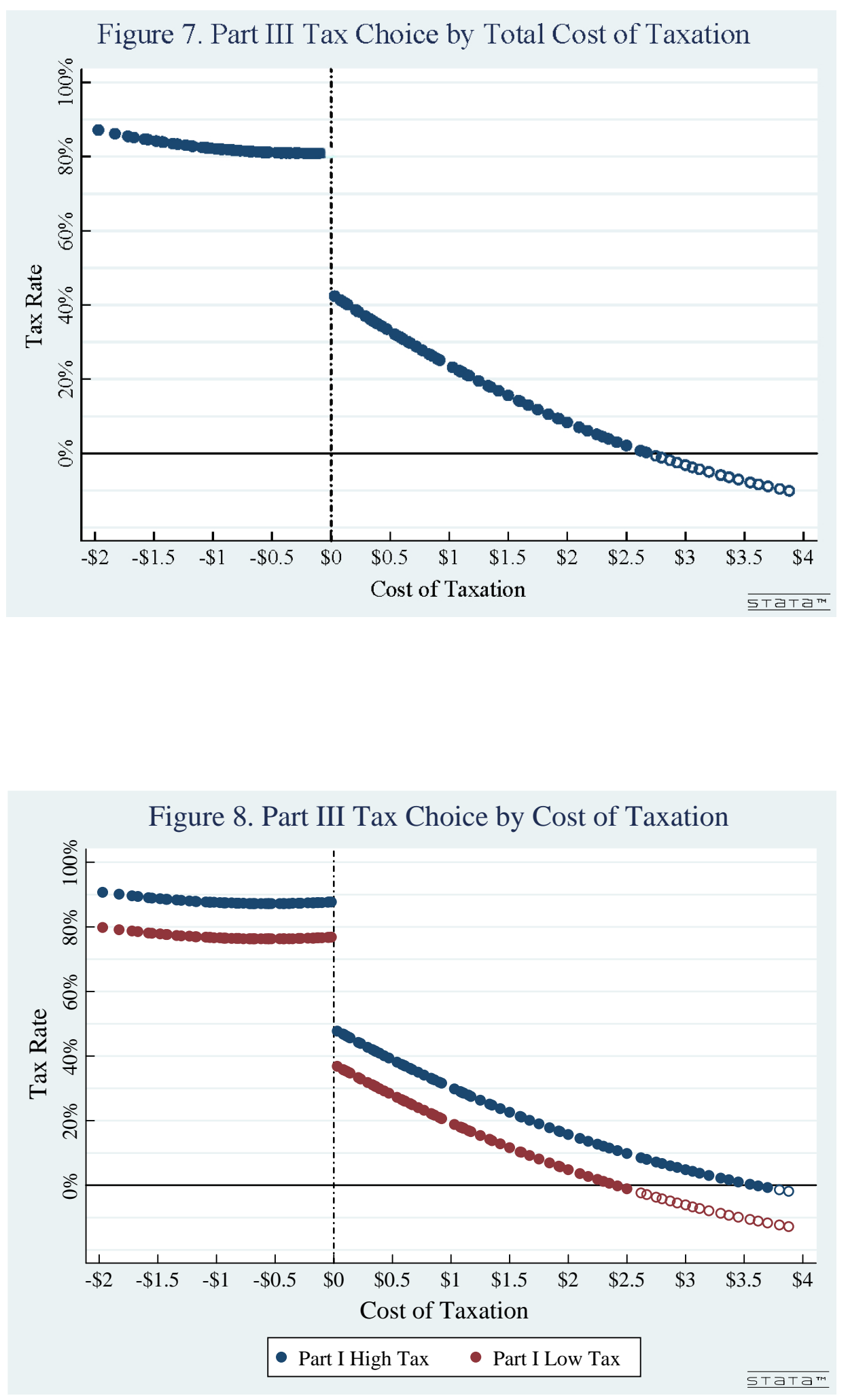
Table 8. Estimates of the Utility Function Parameters

\begin{tabular}{|l|cccc|}
\hline Experimental Condition & $\beta$ & $\gamma$ & $\eta$ & $\delta$ \\
\hline Part I & n.a. & $+(* * *)$ & $-(* * *)$ & $+(* * *)$ \\
Part II (Random method) & -() & $+(* * *)$ & $-(* * *)$ & $+(*)$ \\
Part II (Non-random methods) & +() & $+(* * *)$ & $-(* * *)$ & +() \\
Part III & n.a. & $-(* * *)$ & $-(* * *)$ & -() \\
\hline
\end{tabular}

(*) significant at the $10 \%$ level, $(* *) 5 \%,(* * *) 1 \%$

Figure 9 - Part I Optimal Tax

(a) Very Conservative

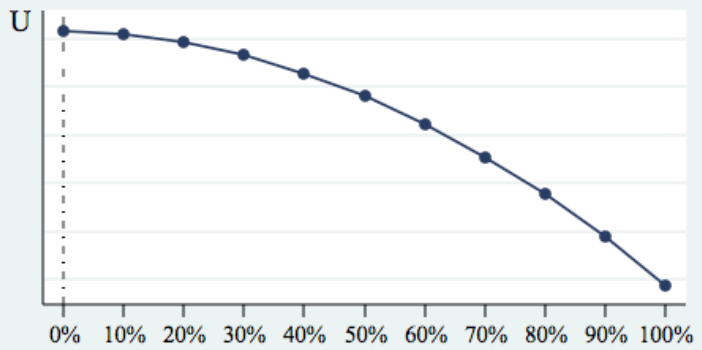

(c) Random Method

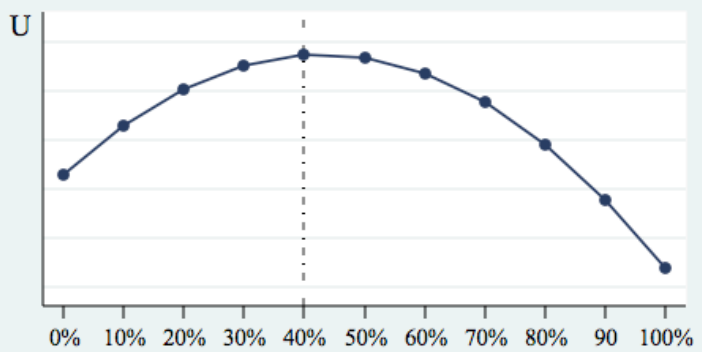

(b) Very Liberal

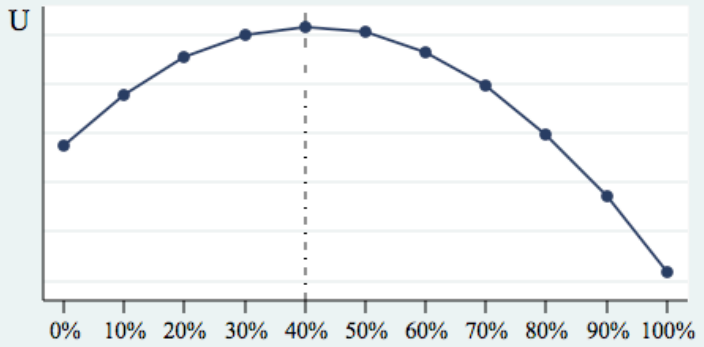

(d) Quiz Method

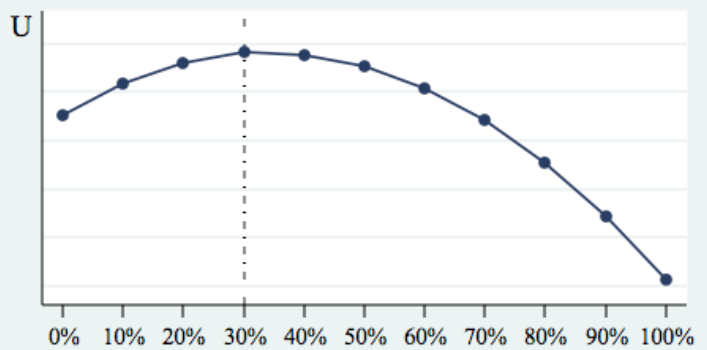




\section{Appendix}

Appendix Table 1. U.S. Individual Income Distribution and Possible Experiment Earnings

\begin{tabular}{|c|c|c|}
\hline Twentieth/Rank & Income & Earnings \\
\hline 1 & $\$ 157,423$ & $\$ 100.00$ \\
2 & $\$ 72,488$ & $\$ 46.05$ \\
3 & $\$ 57,538$ & $\$ 36.55$ \\
4 & $\$ 48,516$ & $\$ 30.82$ \\
5 & $\$ 41,776$ & $\$ 26.54$ \\
6 & $\$ 36,697$ & $\$ 23.31$ \\
7 & $\$ 32,458$ & $\$ 20.62$ \\
8 & $\$ 28,991$ & $\$ 18.42$ \\
9 & $\$ 25,637$ & $\$ 16.29$ \\
10 & $\$ 22,795$ & $\$ 14.48$ \\
11 & $\$ 20,028$ & $\$ 12.72$ \\
12 & $\$ 17,525$ & $\$ 11.13$ \\
13 & $\$ 15,052$ & $\$ 9.56$ \\
14 & $\$ 12,818$ & $\$ 8.14$ \\
15 & $\$ 10,715$ & $\$ 6.81$ \\
16 & $\$ 8,699$ & $\$ 5.53$ \\
17 & $\$ 6,792$ & $\$ 4.31$ \\
18 & $\$ 4,878$ & $\$ 3.10$ \\
19 & $\$ 2,383$ & $\$ 1.51$ \\
20 & $\$ 166$ & $\$ 0.11$ \\
\hline
\end{tabular}

Source: US Census Bureau, 2000 
Appendix Table 2. Distribution of Participants by Personal Characteristics

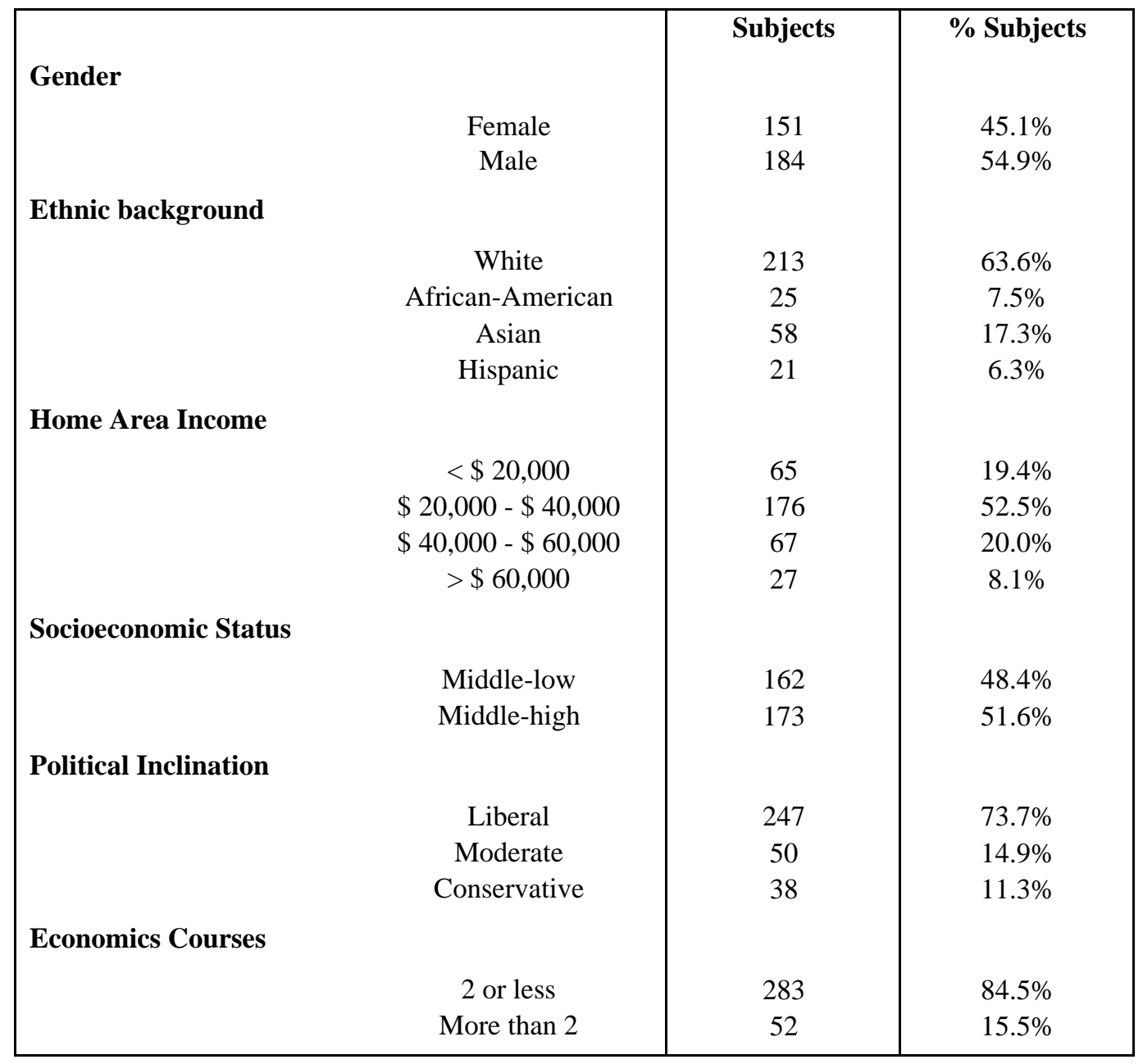




\begin{tabular}{|c|c|c|c|c|c|}
\hline \multicolumn{6}{|c|}{ Appendix Table 3. Distribution of Tax Choices for Part I, II, and III by Method } \\
\hline \multicolumn{6}{|c|}{ Part I (335 subjects, 1340 choices) } \\
\hline & All & Random & Where From & Tetris & Quiz \\
\hline$t=0 \%$ & $23.6 \%$ & $20.0 \%$ & $24.5 \%$ & $25.7 \%$ & $24.2 \%$ \\
\hline$t=10 \%$ & $6.2 \%$ & $3.9 \%$ & $8.1 \%$ & $5.7 \%$ & $7.2 \%$ \\
\hline$t=20 \%$ & $6.6 \%$ & $5.1 \%$ & $5.7 \%$ & $8.4 \%$ & $7.5 \%$ \\
\hline$t=30 \%$ & $11.0 \%$ & $8.1 \%$ & $9.3 \%$ & $13.4 \%$ & $13.1 \%$ \\
\hline$t=40 \%$ & $8.4 \%$ & $8.1 \%$ & $5.1 \%$ & $9.3 \%$ & $11.3 \%$ \\
\hline$t=50 \%$ & $10.2 \%$ & $14.6 \%$ & $7.5 \%$ & $8.4 \%$ & $10.5 \%$ \\
\hline$t=60 \%$ & $5.5 \%$ & $5.4 \%$ & $4.8 \%$ & $6.6 \%$ & $5.1 \%$ \\
\hline$t=70 \%$ & $5.8 \%$ & $5.1 \%$ & $6.6 \%$ & $5.7 \%$ & $6.0 \%$ \\
\hline$t=80 \%$ & $5.2 \%$ & $5.7 \%$ & $5.1 \%$ & $5.4 \%$ & $4.5 \%$ \\
\hline$t=90 \%$ & $3.6 \%$ & $5.1 \%$ & $4.5 \%$ & $3.3 \%$ & $1.5 \%$ \\
\hline$t=100 \%$ & $14.0 \%$ & $19.1 \%$ & $19.1 \%$ & $8.4 \%$ & $9.3 \%$ \\
\hline \multicolumn{6}{|c|}{ Part II (335 subjects, 1340 choices) } \\
\hline & All & Random & Where From & Tetris & Quiz \\
\hline$t=0 \%$ & $21.0 \%$ & $13.1 \%$ & $26.0 \%$ & $25.1 \%$ & $19.7 \%$ \\
\hline$t=10 \%$ & $6.0 \%$ & $3.6 \%$ & $7.5 \%$ & $6.3 \%$ & $6.9 \%$ \\
\hline$t=20 \%$ & $7.2 \%$ & $5.4 \%$ & $5.4 \%$ & $9.3 \%$ & $8.7 \%$ \\
\hline$t=30 \%$ & $11.2 \%$ & $8.7 \%$ & $9.6 \%$ & $13.1 \%$ & $13.4 \%$ \\
\hline$t=40 \%$ & $8.2 \%$ & $8.1 \%$ & $3.6 \%$ & $10.2 \%$ & $11.0 \%$ \\
\hline$t=50 \%$ & $10.5 \%$ & $16.1 \%$ & $5.7 \%$ & $8.7 \%$ & $11.3 \%$ \\
\hline$t=60 \%$ & $5.8 \%$ & $4.8 \%$ & $6.3 \%$ & $5.1 \%$ & $7.2 \%$ \\
\hline$t=70 \%$ & $6.8 \%$ & $7.5 \%$ & $7.5 \%$ & $6.9 \%$ & $5.4 \%$ \\
\hline$t=80 \%$ & $5.1 \%$ & $5.7 \%$ & $5.4 \%$ & $5.1 \%$ & $4.2 \%$ \\
\hline$t=90 \%$ & $4.0 \%$ & $5.1 \%$ & $3.9 \%$ & $3.9 \%$ & $3.3 \%$ \\
\hline$t=100 \%$ & $14.3 \%$ & $22.1 \%$ & $19.4 \%$ & $6.6 \%$ & $9.0 \%$ \\
\hline \multicolumn{6}{|c|}{ Part III (147 subjects, 588 choices) } \\
\hline & All & Random & Where From & Tetris & Quiz \\
\hline$t=0 \%$ & $33.5 \%$ & $35.4 \%$ & $34.7 \%$ & $30.6 \%$ & $33.3 \%$ \\
\hline$t=10 \%$ & $3.9 \%$ & $0.7 \%$ & $5.4 \%$ & $4.8 \%$ & $4.8 \%$ \\
\hline$t=20 \%$ & $1.5 \%$ & $1.4 \%$ & $0.7 \%$ & $3.4 \%$ & $0.7 \%$ \\
\hline$t=30 \%$ & $3.1 \%$ & $3.4 \%$ & $3.4 \%$ & $2.7 \%$ & $2.7 \%$ \\
\hline$t=40 \%$ & $3.1 \%$ & $2.7 \%$ & $1.4 \%$ & $0.7 \%$ & $7.5 \%$ \\
\hline$t=50 \%$ & $3.7 \%$ & $6.8 \%$ & $3.4 \%$ & $2.7 \%$ & $2.0 \%$ \\
\hline$t=60 \%$ & $2.0 \%$ & $2.0 \%$ & $2.0 \%$ & $1.4 \%$ & $2.7 \%$ \\
\hline$t=70 \%$ & $3.2 \%$ & $3.4 \%$ & $2.0 \%$ & $4.8 \%$ & $2.7 \%$ \\
\hline$t=80 \%$ & $2.0 \%$ & $0.7 \%$ & $3.4 \%$ & $2.7 \%$ & $1.4 \%$ \\
\hline$t=90 \%$ & $2.7 \%$ & $2.0 \%$ & $2.7 \%$ & $4.1 \%$ & $2.0 \%$ \\
\hline$t=100 \%$ & $41.2 \%$ & $41.5 \%$ & $40.8 \%$ & $42.2 \%$ & $40.1 \%$ \\
\hline
\end{tabular}




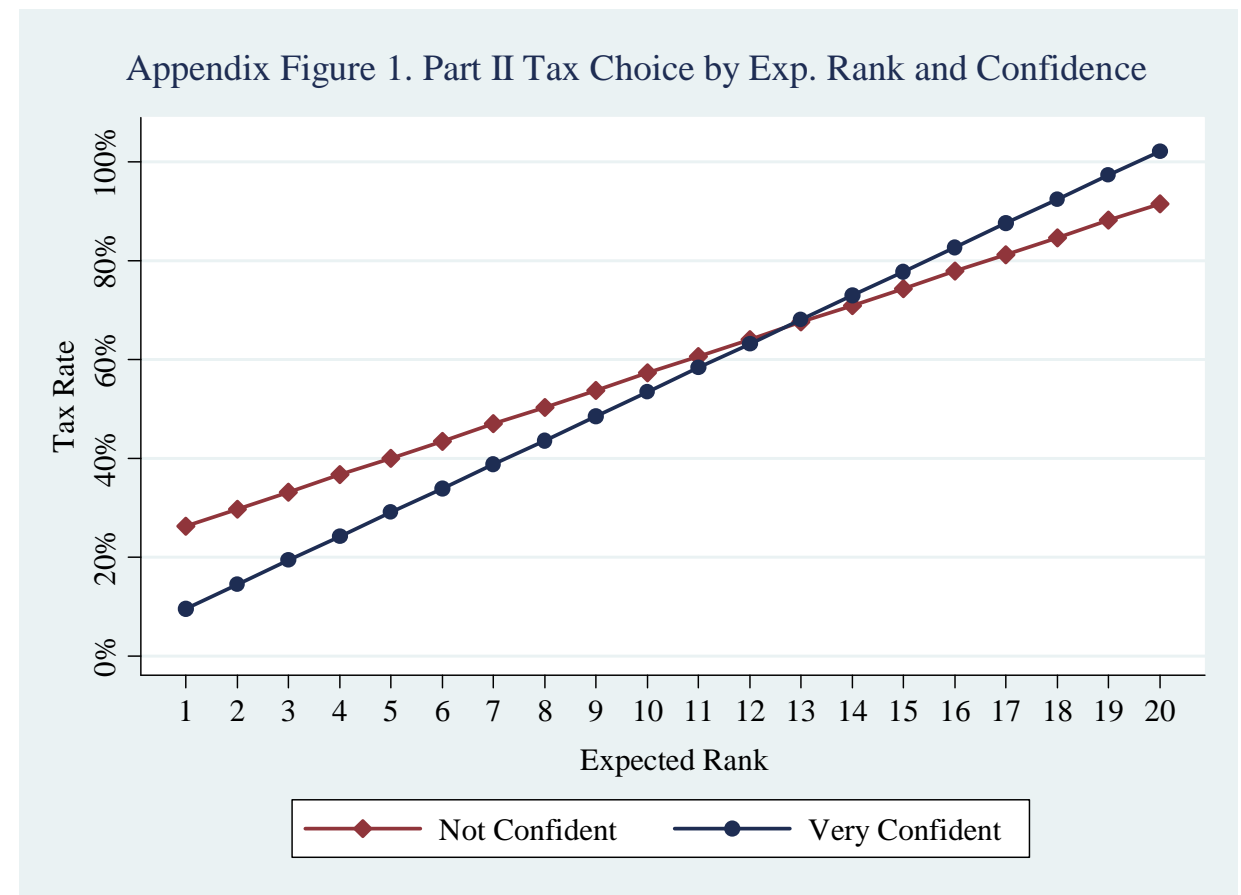

Note: predicted tax choice for a subject of average characteristics, based on coefficients estimated in the Tobit regression shown in column (3) of Table 6. 
Appendix Table 4. Questions used to construct the Political Philosophy and the Socioeconomic Status indicators

\begin{tabular}{|c|c|c|}
\hline \multirow{3}{*}{1.} & Political Phylosophy & \multirow{3}{*}{$\begin{array}{l}\text { Which of the following best describes your political inclination (affiliation)? } \\
\text { Republican; Democrat; Independent; don't know; other }\end{array}$} \\
\hline & Question: & \\
\hline & Possible answers: & \\
\hline \multirow{2}{*}{2.} & Question: & Which of the following best describes your political philosophy (ideology)? \\
\hline & Possible answers: & On a scale of 1 (Very Conservative) to 7 (Very Liberal) \\
\hline \multirow{3}{*}{1.} & Socioeconomic Status & \multirow{3}{*}{$\begin{array}{l}\text { When you were in high school, did your family live in: } \\
\text { an apartment; a single family house; a multi-family house; other }\end{array}$} \\
\hline & Question: & \\
\hline & Possible answers: & \\
\hline \multirow{2}{*}{2.} & Question: & When your father was growing up, were his parents: \\
\hline & Possible answers: & working class ; middle class; upper middle class; rich \\
\hline \multirow{2}{*}{3.} & Question: & When your mother was growing up, were her parents: \\
\hline & Possible answers: & working class ; middle class; upper middle class; rich \\
\hline \multirow{2}{*}{4.} & Question: & When you were growing up, were your parents: \\
\hline & Possible answers: & working class ; middle class; upper middle class; rich \\
\hline \multirow[b]{2}{*}{5.} & Question: & How would you characterize the principal wage-earner in your family? \\
\hline & Possible answers: & $\begin{array}{c}\text { a professional (doctor, lawyer, dentist, accountant, etc.) ; a business person, executive, or manager ; a small } \\
\text { business owner ; an ordinary employee ; other }\end{array}$ \\
\hline \multirow[t]{2}{*}{6.} & Question: & $\begin{array}{l}\text { Considering your family's income, what your family has to live on and the cost of living, } \\
\text { how would you say your family is making out today? }\end{array}$ \\
\hline & Possible answers: & all right ; fairly well ; quite pinched ; not making ends meet \\
\hline
\end{tabular}

